\title{
Trace Element Conundrum of Natural Quasicrystals
}

\author{
Simone Tommasini, Luca Bindi,* Maurizio Petrelli, Paul D. Asimow, and Paul J. Steinhardt
}

Cite This: ACS Earth Space Chem. 2021, 5, 676-689

Read Online

ABSTRACT: We report laser ablation inductively coupled plasma mass spectrometry measurements of the trace element contents of the two naturally occurring quasicrystalline minerals, $\mathrm{Al}_{63} \mathrm{Cu}_{24} \mathrm{Fe}_{13}$ icosahedrite and $\mathrm{Al}_{71} \mathrm{Ni}_{24} \mathrm{Fe}_{5}$ decagonite, from their type locality in the Khatyrka meteorite. The isolated quasicrystal fragments were mounted separately from any matrix and are larger than the laser beam diameter. When the elements are sorted in order of volatility, a systematic and unique pattern emerges in both bulk natural quasicrystal specimens. They are highly depleted compared to primitive solar system materials (chondritic meteorites) in moderately refractory elements (those with $50 \%$ condensation temperatures near $1350-1300 \mathrm{~K}$; V, Co, Mg, Cr) and significantly enriched in moderately volatile elements (those with $50 \%$

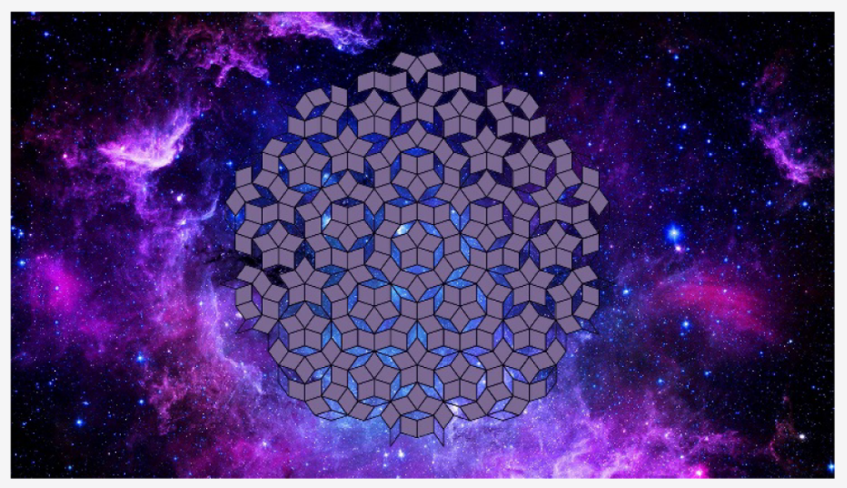
condensation temperatures between 1250 and $500 \mathrm{~K} ; \mathrm{Sb}, \mathrm{B}, \mathrm{Ag}, \mathrm{Sn}, \mathrm{Bi}$ ). We compare the chondrite-normalized trace element patterns and ratios of the quasicrystals to those of scoriaceous cosmic spherules and other meteoritic components. The nonmonotonic shapes of the chondrite-normalized trace element patterns in both icosahedrite and decagonite are incompatible with a single condensation process from the gas of the solar nebula. Previous transmission electron microscopy studies show that the natural quasicrystals contain 3-5 vol \% of silicate and oxide nanoparticle inclusions, which we consider to be the main host of the measured trace elements. On this basis, we construct a three-stage model for the formation of the quasicrystals and their inclusions: a high-temperature condensation stage and a low-temperature vapor-fractionation stage to make nanoparticles, followed by a third stage that leads to the formation of quasicrystals incorporating the two different types of nanoparticles and their incorporation into the CV chondrite parent body of the Khatyrka meteorite.

KEYWORDS: quasicrystal, icosahedrite, decagonite, alloys, trace elements, meteorite, solar system

\section{INTRODUCTION}

Khatyrka is a peculiar CV-type meteorite that contains crystalline $\mathrm{Cu}-\mathrm{Al}$ alloys. ${ }^{1}$ It also contains quasicrystals (QCs), short for "quasiperiodic crystals", 2,3 materials well studied for the last 35 years in the laboratory but exceedingly rare in nature. In fact, Khatyrka is currently the only known natural occurrence. QCs are built from quasiperiodic arrangements of atoms and exhibit rotational symmetries forbidden to ordinary crystals (e.g., fivefold). The origin of these unusual metallic alloys is enigmatic as they contain metallic aluminum, which forms under highly reducing conditions not normally found in nature. Furthermore, the puzzling combination of metallic aluminum, a refractory lithophile element, and copper, a moderately volatile siderophile or chalcophile element, makes these alloys even more mysterious. When first reported, a plausible explanation was that the samples were byproducts of some laboratory or industrial process, and indeed Ivanova et $\mathrm{al}^{4}$ argued for this hypothesis. Previous and successive studies, however, provided compelling evidence that the quasicrystals are natural and from a common meteoritic source, namely, (1) ${ }^{14} \mathrm{C}$-dating of material from undisturbed clay layers where some of the samples were collected yielded $6.7-8.0 \mathrm{ka} \mathrm{BP} ;{ }^{1,5}$
(2) the $\mathrm{Cu}-\mathrm{Al}$ metallic alloys were found to be intimately intermixed with oxides/silicates with nonterrestrial oxygen isotope composition; ${ }^{6}$ (3) clear evidence was found of highpressure-induced phase transitions requiring transient conditions consistent with an asteroidal collision event, at least 5 $\mathrm{GPa}$ and $1200{ }^{\circ} \mathrm{C}$, sufficient to melt and rapidly quench the $\mathrm{Al}-\mathrm{Cu}$ bearing alloys; ${ }^{7}(4)$ noble gas measurements confirmed that the shock event reached pressure above $5 \mathrm{GPa}$ and occurred at least hundreds of million years ago; ${ }^{8}$ and (5) robust petrographic and chemical evidence established that some metallic alloy grains (including quasicrystals) found in the samples predated the shocks. ${ }^{6,7}$ Moreover, the recent discovery of a CO-type chondritic spherule from the Nubian desert, Sudan, ${ }^{9}$ containing the same assemblage of aluminum, iron, and copper and with a morphology remarkably similar to

Received: January 6, 2021

Accepted: February 15, 2021

Published: February 25, 2021 
Khatyrka, provided further support and independent evidence that these samples were formed in outer space. The Khatyrka quasicrystals are currently suspected of having formed in the early solar system through either condensation in the solar nebula or by impact-induced shock metamorphism on the Khatyrka parent body. ${ }^{6-8,10}$

To better understand the origin of these exotic phases and the relationship of Khatyrka to other $\mathrm{CV}$ chondrites, we have measured the trace element abundances of the two known quasicrystalline minerals, icosahedrite, ${ }^{11,12}$ and decagonite. ${ }^{13,14}$ Remarkably, in spite of the fact that QCs appear homogeneous at electron microprobe scale, ${ }^{1,11,12,15}$ electron microscope (SEM, TEM) studies ${ }^{6,15,16}$ have demonstrated the occurrence of silicate/oxide inclusions with particle sizes less than $10 \mathrm{~nm}$ (Figure S1). These nanoparticles make up some 3-5\% of the quasicrystal volume and, as we shall see, appear to be the main hosts of most of the trace element signatures presented in this study.

This study is organized into two parts. First, the trace element signature of the two natural QCs is compared with those of other extraterrestrial objects and shown to have a unique trace element pattern never encountered previously in meteorites. This is likely due to the occurrence of two different types of nanoparticle inclusions in the QCs. Second, based on this unique trace element signature, we describe in the Discussion section a three-stage model for the origin and evolution of these nanoparticles (stages I and II) that eventually were incorporated into QCs during their formation (stage III).

\section{METHODOLOGY}

Materials Studied. Eight quasicrystalline samples were selected for this study. They were initially checked by singlecrystal X-ray diffraction using a Bruker D8 Venture equipped with graphite-monochromatized Mo $\mathrm{K} \alpha$ radiation and then mounted in epoxy and polished. All analyses were conducted not in situ in Khatyrka grains but rather on separated quasicrystal pieces greater than $200 \mu \mathrm{m}$ in the smallest dimension, without adhering meteoritic matrix material. Their chemical compositions were qualitatively measured by energydispersive X-ray spectrometry on a scanning electron microscope (Zeiss-EVO MA15) to develop a comprehensive list of elements for quantitative measurements by an electron microprobe (JEOL JXA-8600). Each fragment was homogeneous within analytical error. The same samples were then analyzed by laser ablation inductively coupled plasma mass spectrometry (LA-ICPMS).

In detail, we studied

- two fragments of icosahedrite (icosahedral symmetry) from the Khatyrka meteorite (labeled NI1 and NI2; NI = natural icosahedrite); such fragments are not part of the holotype material (MSNF_46407/G) ${ }^{12}$ but were found in successive searches through the materials brought back from the expedition to the Koryak Mountains in the Chukotka Autonomous Okrug of Far Eastern Russia; ${ }^{16,17}$

- two fragments of decagonite (decagonal symmetry) from the Khatyrka meteorite (labeled ND1 and ND2; $\mathrm{ND}=$ natural decagonite); such fragments are neither part of the holotype meteorite material (MSNF_46407/ $\mathrm{G})^{1}$ nor of the decagonite holotype (MSNF_3143/I) but rather are from the same additional recovered material as NI1 and NI2;

- two specimens of synthetic icosahedrite and two specimens of synthetic decagonite, prepared in each case from high-purity metals, as references and blanks (see the Supporting Information).

SEM-BSE images of the four natural quasicrystals are given in Figure 1. Electron microprobe analyses of the four natural quasicrystals investigated are reported in Table 1.

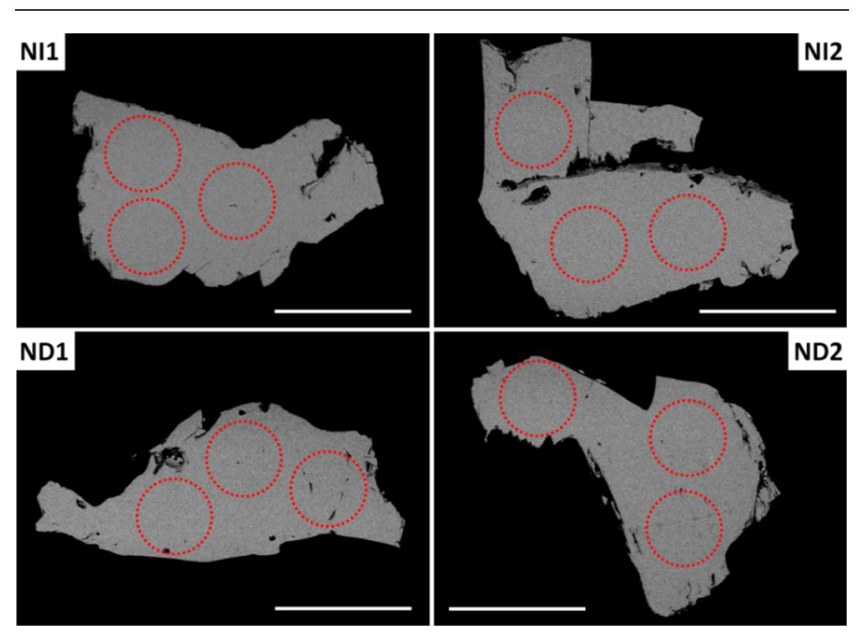

Figure 1. Scanning electron microscope backscattered electron images of the four natural quasicrystals (icosahedrite: NI1 and NI2; decagonite: ND1 and ND2) investigated. Red dashed circles indicated the spots $(110 \mu \mathrm{m}$ in diameter $)$ obtained for each sample. The scale bar is $200 \mu \mathrm{m}$.

Analytical Methods. The trace element concentrations were determined by laser ablation inductively coupled plasma mass spectrometry (LA-ICPMS) at the Department of Physics and Geology, University of Perugia, Italy. ${ }^{18-20}$ The analyses were carried out with a Teledyne Photon Machine G2 laser ablation system coupled to a Thermo Fisher Scientific iCAP-Q quadrupole-based ICPMS. The unknown samples were analyzed using a circular $193 \mathrm{~nm}$ laser beam focused to a spot diameter on the sample surface of $110 \mu \mathrm{m}$, a pulse repetition frequency of $10 \mathrm{~Hz}, 5 \mathrm{~ns}$ pulses, and a laser density on the sample surface of $\sim 3.5 \mathrm{~J} / \mathrm{cm}^{2}$. Ablation times were about $40 \mathrm{~s}$ per spot, preceded by a $30 \mathrm{~s}$ background measurement and followed by $30 \mathrm{~s}$ of washout.

Before the analytical session, the LA-ICPMS operating conditions were optimized by continuous ablation of NIST SRM 612 glass reference material ${ }^{21}$ to provide maximum signal intensity, stability for the ions of interest, and minimum potential interferences. The sensitivity and the stability of the system were then evaluated on ${ }^{139} \mathrm{La},{ }^{208} \mathrm{~Pb},{ }^{232} \mathrm{Th}$, and ${ }^{238} \mathrm{U}$ by a short-term stability test. It consisted of five acquisitions (one minute each) on a linear scan of NIST SRM 612 glass reference material.

The effects of potential interferences related to polyatomic compounds such as oxides $\left(\mathrm{MO}^{+}\right.$, where $\mathrm{M}$ is a metal atom) and argides $\left(\mathrm{ArM}^{+}\right)$or to doubly charged ions $\left(\mathrm{M}^{++}\right)$have been carefully evaluated as part of our assessment of the accuracy of the reported determinations. The $\mathrm{ThO}^{+} / \mathrm{Th}^{+}$ratio was used as a proxy for oxide production, given that $\mathrm{Th}-\mathrm{O}$ is among the strongest $\mathrm{M}-\mathrm{O}$ bonds with a binding energy of $878.9 \mathrm{~kJ} \mathrm{~mol}^{-1} .^{22}$ As a consequence, the $\mathrm{ThO}^{+} / \mathrm{Th}^{+}$ratio is 


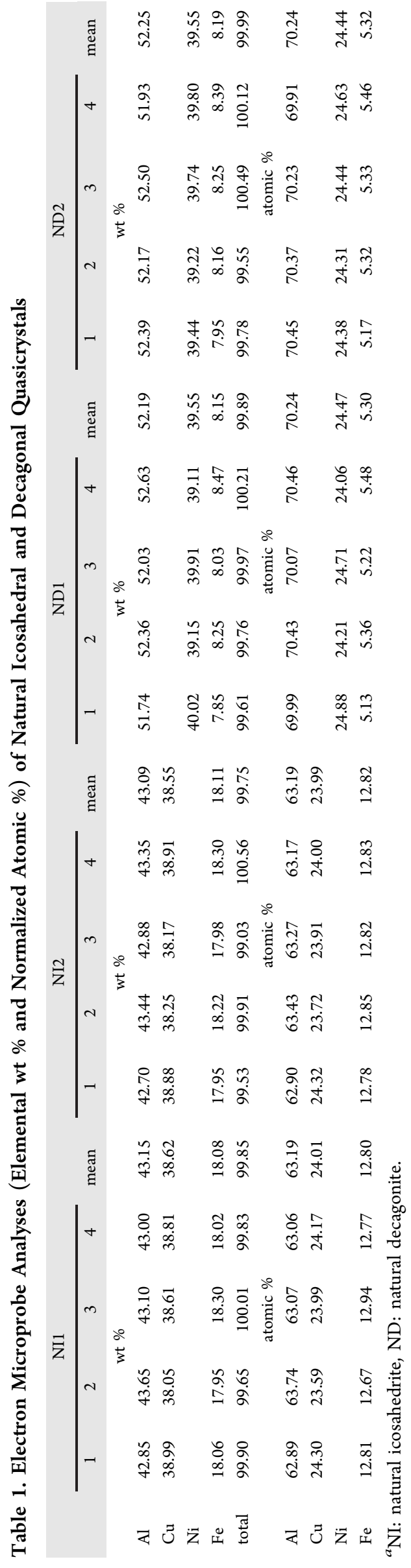

expected to provide an upper bound on the abundances of all other oxide clusters relative to their free metal ions. In detail, the $\mathrm{ThO}^{+} / \mathrm{Th}^{+}$ratio was monitored during the tuning process and maintained below $0.5 \%$. Starting from the measured value of $\mathrm{ThO}^{+} / \mathrm{Th}^{+}$, all other $\mathrm{MO}^{+} / \mathrm{M}^{+}$ratios are estimated from their relative $\mathrm{M}-\mathrm{O}$ binding energies. ${ }^{23}$ The $0.5 \%$ ceiling on $\mathrm{ThO}^{+} / \mathrm{Th}^{+}$implies that the maximum effects of oxide interferences on the target analytes are, for example, $50 \mu \mathrm{g} / \mathrm{g}$ of oxide for an element present in the sample at $10000 \mu \mathrm{g} / \mathrm{g}$ or $0.5 \mu \mathrm{g} / \mathrm{g}$ of oxide for $100 \mu \mathrm{g} / \mathrm{g}$ of an element, etc. These maximum values are correct for a few elements like $\mathrm{Th}$ and $\mathrm{Ta}$. All of the other elements are characterized by lower oxide production, often negligible even at wt \% concentration. To be conservative, we used the maximum threshold of $0.5 \%$ for all $\mathrm{MO}^{+} / \mathrm{M}^{+}$and we monitored all elements present at or above $10 \mu \mathrm{g} / \mathrm{g}$ to intercept maximum potential interferences above $0.05 \mu \mathrm{g} / \mathrm{g}$. We excluded from the analyses all of the elements potentially affected by oxide interferences of $\mathrm{Cu}, \mathrm{Al}, \mathrm{Fe}$, and $\mathrm{Ni}$.

In LA-ICPMS, argide ions (e.g., $\mathrm{ArM}^{+}$) can significantly affect specific elements. Examples are the interferences by ${ }^{59} \mathrm{Co}^{40} \mathrm{Ar},{ }^{61} \mathrm{Ni}^{40} \mathrm{Ar},{ }^{63} \mathrm{Cu}^{40} \mathrm{Ar},{ }^{65} \mathrm{Cu}^{40} \mathrm{Ar}$, and ${ }^{66} \mathrm{Zn}{ }^{40} \mathrm{Ar}$ on light PGEs like ${ }^{99} \mathrm{Ru},{ }^{101} \mathrm{Ru},{ }^{103} \mathrm{Rh},{ }^{105} \mathrm{Pd}$, and ${ }^{106} \mathrm{Pd}$. ${ }^{24}$ In the present study, we excluded from the analytical protocol all of the isotopes potentially affected by interferences related to argide ion production.

The formation of significant doubly charged ions $\left(\mathrm{M}^{++}\right)$ occurs for elements characterized by low second ionization potentials like $\mathrm{Be}, \mathrm{Mg}, \mathrm{Ca}, \mathrm{Cu}, \mathrm{Sr}, \mathrm{Ba}, \mathrm{Pb}$, and all of the rareearth elements. ${ }^{25}$ Operating the ICPMS at the unit mass resolution can cause anomalous counts at half the mass of the doubled-charged ion (rounded up for odd masses). Among the studied analytes, potentially affected isotopes are ${ }^{71} \mathrm{Ga}\left({ }^{141} \mathrm{Pr}\right.$, $\left.{ }^{142} \mathrm{Nd},{ }^{142} \mathrm{Ce}\right),{ }^{75} \mathrm{As}\left({ }^{149} \mathrm{Sm},{ }^{150} \mathrm{Sm},{ }^{150} \mathrm{Nd}\right)$, and ${ }^{88} \mathrm{Sr}\left({ }^{175} \mathrm{Lu}\right.$, $\left.{ }^{176} \mathrm{Yb},{ }^{176} \mathrm{Hf},{ }^{176} \mathrm{Lu}\right)$. However, under the analytical conditions utilized for this study, the effects of doubly charged ions are negligible for all unknown quasicrystals and quality controls.

A major problem in obtaining reliable LA-ICPMS trace element analyses of metal alloys $(\mathrm{Al}-\mathrm{Fe}-\mathrm{Cu}-\mathrm{Ni}$ alloys in this specific case) is that, unlike currently available silicate glass standards, most available metal alloy standards do not have a complete set of certified trace element contents. In general, the available metal alloy standards are well characterized for platinum group elements but other trace elements, if reported in their certificates at all, are not homogeneously distributed in the reference material ${ }^{26}$ and cannot be used as quality control. In the present case, no $\mathrm{Al}-\mathrm{Cu}$ alloy standard with a complete and homogeneously distributed set of trace elements is currently available and furthermore we seek to quantify a set of trace elements not available in other metal alloy standards.

On the other hand, using a silicate glass standard as calibration reference material may cause poor accuracy on the unknowns to be analyzed because of matrix-matching problems. The best compromise that we have adopted has been to use NIST SRM 610 silicate glass standard ${ }^{21}$ as calibrator reference material and to evaluate systematic errors by comparison with three metal alloy standards during each QC analytical session. The metal alloy standards adopted are HOBA, NORTH CHILE, and NIST SRM 1262b reference materials. For each reference material, we calculated the relative sensitivity factors (RSFs) normalized to $\mathrm{Al}$ and Fe. The results are reported in Figure S2, which shows that both Al- 
Table 2. Trace Element Analyses $(\mu \mathrm{g} / \mathrm{g})$ of Natural Icosahedrite and Decagonite

\begin{tabular}{|c|c|c|c|c|c|c|c|}
\hline \multicolumn{8}{|c|}{ icosahedrite } \\
\hline & LOD & NI1_01 & NI1_02 & NI1_03 & NI1_01 & NI2_02 & NI2_03 \\
\hline B & $(3-3.4)$ & - & - & $<4.5$ & $<4$ & $<6.8$ & - \\
\hline $\mathrm{Na}$ & $(12-16)$ & $183 \pm 72$ & - & $<19$ & $202 \pm 78$ & $55 \pm 19$ & $220 \pm 120$ \\
\hline $\mathrm{Mg}$ & $(1.1-1.6)$ & $12.9 \pm 3.0$ & - & $13 \pm 10$ & $53 \pm 39$ & $14.8 \pm 3.4$ & $51 \pm 29$ \\
\hline $\mathbf{K}$ & $(2.5-4.2)$ & $46 \pm 14$ & $52 \pm 23$ & $<7$ & $47 \pm 34$ & $18.5 \pm 7.4$ & $44 \pm 24$ \\
\hline $\mathbf{T i}$ & $(2.1-2.2)$ & - & - & - & $<9.1$ & - & $<2.5$ \\
\hline $\mathbf{V}$ & $(0.18-0.24)$ & $1.54 \pm 0.76$ & $5.3 \pm 2.9$ & $<2.5$ & $2.3 \pm 1.6$ & $0.88 \pm 0.15$ & $1.04 \pm 0.27$ \\
\hline $\mathrm{Cr}$ & $(1.8-2.7)$ & $130 \pm 32$ & $104 \pm 17$ & $83 \pm 14$ & $121 \pm 26$ & $129 \pm 30$ & $113 \pm 28$ \\
\hline Mn & $(1.3-1.7)$ & $30.6 \pm 8.8$ & $20.3 \pm 4.1$ & $16 \pm 2.6$ & $31.7 \pm 7.8$ & $24.9 \pm 4.9$ & $25.4 \pm 9.0$ \\
\hline Co & $(0.17-0.23)$ & $5.44 \pm 0.82$ & $4.8 \pm 2.1$ & $3.35 \pm 0.48$ & $5.06 \pm 0.61$ & $4.55 \pm 0.47$ & $4.31 \pm 0.61$ \\
\hline $\mathrm{Zn}$ & $(0.5-0.7)$ & $134 \pm 31$ & $105 \pm 20$ & $123 \pm 23$ & $213 \pm 42$ & $117 \pm 20$ & $94 \pm 23$ \\
\hline Ga & $(0.042-0.11)$ & $12.4 \pm 1.3$ & $12.2 \pm 1.1$ & $12.0 \pm 1.2$ & $12.2 \pm 1.4$ & $13.2 \pm 2.3$ & $11.8 \pm 1.4$ \\
\hline As & $(0.49-0.77)$ & $1.04 \pm 0.36$ & $<1.4$ & $<0.77$ & $1.28 \pm 0.40$ & $(1.7) \pm 1.8$ & $<1.3$ \\
\hline $\mathbf{R b}$ & $(0.12-0.14)$ & $<0.30$ & $0.46 \pm 0.27$ & $<0.16$ & $<0.13$ & $<0.20$ & $<0.48$ \\
\hline $\mathbf{S r}$ & $(0.004-0.014)$ & $0.88 \pm 0.29$ & - & $0.42 \pm 0.25$ & $1.16 \pm 0.38$ & $0.85 \pm 0.30$ & $1.52 \pm 0.44$ \\
\hline $\mathbf{Y}$ & $(0.004-0.017)$ & $6.52 \pm 0.37$ & $6.89 \pm 0.63$ & $5.12 \pm 0.38$ & $6.02 \pm 0.51$ & $5.90 \pm 0.52$ & $6.30 \pm 0.60$ \\
\hline $\mathrm{Zr}$ & $(0.007-0.017)$ & $3.10 \pm 0.61$ & $7.6 \pm 4.1$ & $12.1 \pm 6.9$ & $4.2 \pm 1.6$ & $6.6 \pm 3.6$ & $2.53 \pm 0.40$ \\
\hline $\mathrm{Nb}$ & $(0.004-0.016)$ & $0.082 \pm 0.031$ & $0.5 \pm 0.3$ & $0.054 \pm 0.036$ & $0.19 \pm 0.16$ & $<0.24$ & $0.24 \pm 0.13$ \\
\hline Mo & $(0.09-0.22)$ & $2.31 \pm 0.93$ & $2.06 \pm 0.55$ & $1.30 \pm 0.46$ & $2.8 \pm 1.3$ & $1.67 \pm 0.43$ & $1.37 \pm 0.34$ \\
\hline $\mathrm{Ag}$ & $(0.041-0.057)$ & - & $5.77 \pm 0.67$ & $7.5 \pm 3.1$ & $8.2 \pm 2.0$ & $7.4 \pm 1.3$ & $5.47 \pm 0.57$ \\
\hline Cd & $(0.32-0.53)$ & $0.71 \pm 0.31$ & $1.08 \pm 0.61$ & - & $<0.62$ & $0.86 \pm 0.40$ & $<1.28$ \\
\hline Sn & $(0.12-0.16)$ & - & $31.2 \pm 8.4$ & $33 \pm 24$ & $82 \pm 41$ & $105 \pm 46$ & $31.4 \pm 6.1$ \\
\hline $\mathrm{Sb}$ & $(0.13-0.17)$ & $0.73 \pm 0.15$ & $1.7 \pm 1.5$ & $1.33 \pm 0.76$ & $0.69 \pm 0.14$ & $0.82 \pm 0.17$ & $0.63 \pm 0.13$ \\
\hline $\mathbf{B a}$ & $(0.026-0.067)$ & $0.60 \pm 0.38$ & - & $0.35 \pm 0.28$ & $1.31 \pm 0.87$ & $0.91 \pm 0.42$ & $0.90 \pm 0.62$ \\
\hline La & $(0.003-0.017)$ & $0.034 \pm 0.019$ & $0.65 \pm 0.43$ & $<0.056$ & $<0.085$ & $<1.0$ & $0.016 \pm 0.012$ \\
\hline $\mathrm{Ce}$ & $(0.003-0.008)$ & $<0.36$ & - & $0.025 \pm 0.018$ & $<0.29$ & $0.037 \pm 0.023$ & $<0.11$ \\
\hline $\operatorname{Pr}$ & $(0.002-0.009)$ & $<0.10$ & $0.15 \pm 0.12$ & - & $0.14 \pm 0.10$ & $<0.037$ & $<0.031$ \\
\hline $\mathrm{Nd}$ & $(0.03-0.08)$ & $0.35 \pm 0.22$ & $0.62 \pm 0.39$ & $<0.17$ & - & $0.64 \pm 0.37$ & $0.33 \pm 0.18$ \\
\hline Sm & $(0.019-0.045)$ & - & $0.31 \pm 0.16$ & - & $<0.13$ & $<0.034$ & - \\
\hline Eu & $(0.005-0.012)$ & - & $<0.03$ & $<0.07$ & $<0.20$ & $<0.006$ & - \\
\hline Gd & $(0.019-0.049)$ & $0.056 \pm 0.048$ & $<0.12$ & $<0.043$ & $<0.055$ & $<0.047$ & $<0.057$ \\
\hline $\mathrm{Tb}$ & $(0.003-0.008)$ & $0.025 \pm 0.016$ & $0.031 \pm 0.017$ & $<0.008$ & $<0.039$ & $<0.016$ & $<0.015$ \\
\hline Dy & $(0.012-0.038)$ & $<0.012$ & $0.15 \pm 0.11$ & $<0.022$ & $<0.042$ & - & $<0.074$ \\
\hline Ho & $(0.003-0.008)$ & $0.025 \pm 0.023$ & $0.028 \pm 0.020$ & $<0.013$ & $<0.023$ & $<0.008$ & $<0.004$ \\
\hline Er & $(0.009-0.022)$ & $<0.027$ & $0.07 \pm 0.04$ & $<0.03$ & $<0.015$ & - & $<0.021$ \\
\hline $\mathrm{Tm}$ & $(0.003-0.008)$ & - & $0.022 \pm 0.015$ & $<0.01$ & $0.071 \pm 0.060$ & $<0.011$ & $<0.016$ \\
\hline Hf & $(0.01-0.028)$ & $0.104 \pm 0.055$ & $0.19 \pm 0.10$ & $0.159 \pm 0.098$ & $0.16 \pm 0.11$ & $0.21 \pm 0.15$ & $0.102 \pm 0.062$ \\
\hline $\mathrm{Ta}$ & $(0.003-0.008)$ & $<0.09$ & $0.07 \pm 0.04$ & $0.023 \pm 0.018$ & $<0.10$ & $<0.02$ & $<0.056$ \\
\hline $\mathbf{W}$ & $(0.07-0.1)$ & $1.09 \pm 0.47$ & $0.46 \pm 0.19$ & $<2.4$ & $1.90 \pm 1.60$ & $<1.2$ & $0.40 \pm 0.18$ \\
\hline $\operatorname{Re}$ & $(0.008-0.009)$ & $<0.023$ & $<0.018$ & $<0.14$ & $<0.058$ & - & $<0.025$ \\
\hline $\mathrm{Tl}$ & $(0.005-0.014)$ & $0.39 \pm 0.26$ & $0.24 \pm 0.15$ & - & $0.23 \pm 0.18$ & $<0.21$ & $<0.45$ \\
\hline $\mathrm{Pb}$ & $(0.043-0.081)$ & $5.50 \pm 1.20$ & $4.31 \pm 0.79$ & $4.40 \pm 1.80$ & $7.4 \pm 2.4$ & $4.8 \pm 1.2$ & $4.56 \pm 0.95$ \\
\hline $\mathbf{B i}$ & $(0.011-0.047)$ & $1.84 \pm 0.97$ & $0.69 \pm 0.19$ & $1.12 \pm 0.73$ & $1.29 \pm 0.33$ & $1.10 \pm 0.48$ & $<1.5$ \\
\hline Th & $(0.004-0.005)$ & $<0.035$ & $0.52 \pm 0.33$ & $<0.008$ & $0.10 \pm 0.07$ & $<0.01$ & $<0.021$ \\
\hline \multicolumn{8}{|c|}{ decagonite } \\
\hline & LOD & ND1_01 & ND1_02 & ND1_03 & ND2_01 & ND2_02 & ND2_03 \\
\hline B & $(4.4-5.2)$ & $40 \pm 7$ & $128 \pm 36$ & $51.2 \pm 8$ & $27.8 \pm 6$ & $41 \pm 10$ & $107 \pm 15$ \\
\hline $\mathrm{Na}$ & $(19-22)$ & $130 \pm 100$ & $52 \pm 17$ & $44 \pm 17$ & $54 \pm 26$ & $36 \pm 15$ & $<21$ \\
\hline $\mathrm{Mg}$ & $(1.4-3.1)$ & $166 \pm 54$ & $102 \pm 21$ & $69 \pm 12$ & $41 \pm 9$ & $72 \pm 16$ & $56 \pm 11$ \\
\hline $\mathbf{K}$ & $(4.5-6)$ & $45 \pm 27$ & $12.1 \pm 4.5$ & $12.3 \pm 4$ & $28 \pm 5$ & $<7.1$ & $<8.6$ \\
\hline $\mathbf{T i}$ & $(1.5-3.3)$ & $25 \pm 10$ & $38 \pm 12$ & $<3.7$ & - & - & $<3.7$ \\
\hline $\mathbf{V}$ & $(0.25-0.33)$ & $0.72 \pm 0.33$ & $0.76 \pm 0.22$ & - & $<0.35$ & - & $<0.32$ \\
\hline $\mathrm{Cr}$ & $(2.6-3.7)$ & $14 \pm 10$ & $58 \pm 10$ & $13.4 \pm 3.6$ & $13.5 \pm 5.7$ & $10.1 \pm 5.7$ & $17.8 \pm 5.1$ \\
\hline Mn & $(1.8-2.2)$ & $13.3 \pm 6.1$ & $13 \pm 11$ & $<8$ & $<2.4$ & $<3$ & $5.9 \pm 2.0$ \\
\hline Co & $(0.27-0.36)$ & $2.61 \pm 0.73$ & $3.60 \pm 0.62$ & $1.56 \pm 0.32$ & $2.07 \pm 0.48$ & $1.51 \pm 0.29$ & $2.48 \pm 0.42$ \\
\hline $\mathrm{Zn}$ & $(0.55-1.1)$ & $6.0 \pm 1.4$ & $6.3 \pm 1.2$ & $7.0 \pm 1.3$ & $6.3 \pm 2.7$ & $4.16 \pm 0.98$ & $7.1 \pm 2.4$ \\
\hline Ga & $(0.05-0.08)$ & - & - & - & - & - & - \\
\hline As & $(0.77-0.98)$ & $<1.24$ & - & $<1.64$ & $<1.38$ & $1.53 \pm 0.62$ & $<1.14$ \\
\hline $\mathbf{R b}$ & $(0.17-0.2)$ & $<0.60$ & - & - & $<0.43$ & - & - \\
\hline $\mathrm{Sr}$ & $(0.005-0.03)$ & $0.49 \pm 0.15$ & $0.20 \pm 0.06$ & $0.21 \pm 0.06$ & $0.15 \pm 0.06$ & - & $0.17 \pm 0.07$ \\
\hline
\end{tabular}


Table 2. continued

\begin{tabular}{|c|c|c|c|c|c|c|c|}
\hline \multicolumn{8}{|c|}{ decagonite } \\
\hline & LOD & ND1_01 & ND1_02 & ND1_03 & ND2_01 & ND2_02 & ND2_03 \\
\hline $\mathbf{Y}$ & $(0.006-0.039)$ & $1.06 \pm 0.32$ & $0.79 \pm 0.14$ & $0.48 \pm 0.13$ & $0.31 \pm 0.08$ & $0.43 \pm 0.09$ & $0.51 \pm 0.14$ \\
\hline $\mathrm{Zr}$ & $(0.01-0.034)$ & $2.7 \pm 1.4$ & $1.83 \pm 0.53$ & $0.50 \pm 0.28$ & $0.45 \pm 0.20$ & $0.30 \pm 0.11$ & $1.02 \pm 0.28$ \\
\hline $\mathrm{Nb}$ & $(0.005-0.025)$ & $0.64 \pm 0.34$ & $0.58 \pm 0.12$ & $0.52 \pm 0.21$ & $0.22 \pm 0.07$ & $0.54 \pm 0.13$ & $0.68 \pm 0.19$ \\
\hline Mo & $(0.15-0.3)$ & $<0.59$ & $0.77 \pm 0.32$ & $<0.16$ & - & - & - \\
\hline $\mathrm{Ag}$ & $(0.044-0.1)$ & $0.22 \pm 0.11$ & $0.21 \pm 0.11$ & $<0.07$ & $<0.14$ & $<0.23$ & $<0.08$ \\
\hline $\mathrm{Cd}$ & $(0.41-0.71)$ & $<0.81$ & $1.24 \pm 0.68$ & $<0.77$ & $<0.84$ & $<0.63$ & $<0.66$ \\
\hline Sn & $(0.12-0.17)$ & $10.0 \pm 1.9$ & - & $11.0 \pm 2.4$ & $5.9 \pm 1.5$ & $7.7 \pm 1.4$ & $15.2 \pm 3.2$ \\
\hline$S b$ & $(0.19-0.25)$ & $1.0 \pm 0.2$ & $1.57 \pm 0.31$ & $0.74 \pm 0.24$ & $0.53 \pm 0.19$ & $0.68 \pm 0.18$ & $0.85 \pm 0.24$ \\
\hline Ba & $(0.035-0.093)$ & $1.63 \pm 0.78$ & $0.48 \pm 0.23$ & $0.31 \pm 0.17$ & - & $0.36 \pm 0.23$ & $0.32 \pm 0.21$ \\
\hline $\mathbf{L a}$ & $(0.005-0.087)$ & $0.49 \pm 0.13$ & $0.178 \pm 0.055$ & $0.147 \pm 0.050$ & $0.273 \pm 0.093$ & $0.224 \pm 0.068$ & $0.304 \pm 0.070$ \\
\hline $\mathrm{Ce}$ & $(0.004-0.026)$ & $1.11 \pm 0.30$ & $0.33 \pm 0.11$ & $0.32 \pm 0.12$ & $0.62 \pm 0.39$ & $0.42 \pm 0.11$ & $0.50 \pm 0.14$ \\
\hline Pr & $(0.004-0.02)$ & $0.157 \pm 0.068$ & $0.045 \pm 0.020$ & $0.044 \pm 0.017$ & $0.056 \pm 0.026$ & $<0.041$ & $<0.039$ \\
\hline Nd & $(0.044-0.05)$ & $0.43 \pm 0.20$ & $<0.13$ & - & $<0.14$ & $0.21 \pm 0.15$ & $0.33 \pm 0.22$ \\
\hline $\mathrm{Sm}$ & $(0.025-0.061)$ & $<0.081$ & - & - & - & - & $<0.069$ \\
\hline Eu & $(0.007-0.02)$ & - & - & - & $<0.07$ & $<0.029$ & $<0.016$ \\
\hline Gd & $(0.027-0.11)$ & $<0.127$ & $<0.032$ & - & $<0.048$ & $<0.06$ & - \\
\hline $\mathbf{T b}$ & $(0.004-0.005)$ & $0.066 \pm 0.031$ & $<0.016$ & - & $<0.007$ & $<0.012$ & $<0.015$ \\
\hline Dy & $(0.016-0.018)$ & $<0.047$ & $<0.031$ & - & - & - & - \\
\hline Ho & $(0.004-0.005)$ & $0.053 \pm 0.025$ & $<0.007$ & - & - & $<0.013$ & - \\
\hline Er & $(0.012-0.062)$ & $1.57 \pm 0.46$ & $1.3 \pm 0.29$ & $3.3 \pm 1.10$ & $0.52 \pm 0.17$ & $1.28 \pm 0.29$ & $2.41 \pm 0.87$ \\
\hline $\mathrm{Tm}$ & $(0.004-0.015)$ & $0.056 \pm 0.033$ & $0.052 \pm 0.026$ & $0.037 \pm 0.028$ & $<0.013$ & $0.044 \pm 0.025$ & $0.198 \pm 0.095$ \\
\hline Hf & $(0.015-0.039)$ & $1.85 \pm 0.52$ & - & $4.1 \pm 1.7$ & $1.51 \pm 0.44$ & $1.39 \pm 0.41$ & $2.14 \pm 0.73$ \\
\hline Ta & $(0.004-0.012)$ & $0.062 \pm 0.044$ & $<0.016$ & - & $<0.021$ & $<0.011$ & $<0.014$ \\
\hline W & $(0.019-0.16)$ & $0.72 \pm 0.20$ & $0.47 \pm 0.16$ & $0.30 \pm 0.10$ & $(2.0) \pm 2.2$ & $0.82 \pm 0.29$ & $1.00 \pm 0.38$ \\
\hline $\operatorname{Re}$ & $(0.011-0.013)$ & $0.098 \pm 0.047$ & $0.134 \pm 0.066$ & $0.102 \pm 0.048$ & $<0.047$ & $0.084 \pm 0.046$ & $0.057 \pm 0.040$ \\
\hline $\mathrm{Tl}$ & $(0.008-0.009)$ & - & $<0.025$ & - & - & - & $<0.014$ \\
\hline $\mathrm{Pb}$ & $(0.07-0.17)$ & $0.73 \pm 0.26$ & $3.0 \pm 1.3$ & $0.46 \pm 0.12$ & $0.41 \pm 0.16$ & $0.41 \pm 0.15$ & $0.81 \pm 0.27$ \\
\hline $\mathbf{B i}$ & $(0.021-0.062)$ & $3.8 \pm 1.0$ & $3.06 \pm 0.55$ & $4.70 \pm 1.50$ & $1.6 \pm 0.32$ & $3.8 \pm 1.3$ & $3.33 \pm 0.77$ \\
\hline Th & $(0.006-0.007)$ & $0.131 \pm 0.066$ & $<0.009$ & $<0.043$ & $<0.015$ & $<0.016$ & $<0.023$ \\
\hline
\end{tabular}

${ }^{a}$ Each single spot analysis is given with associated error $(1 \sigma)$. Elemental concentrations reported as " $<$ value" are at a semiquantitative level $\left(C^{\mathrm{el}}-\right.$ $1 \sigma<\mathrm{LOD}$, see the Results section of the text); LOD: range $(\mu \mathrm{g} / \mathrm{g})$ of the limit of detection during an analytical session; -: below the detection limit.

and Fe-normalized RSFs of the metal matrixes and silicate glass matrix are in good agreement. Some exceptions are related to those elements heterogeneously distributed in the metal alloys (e.g., $\mathrm{Zr}, \mathrm{Ti}$ ), but the trace element ratios that will be used in this study (to the right of both panels in Figure S2) are in excellent agreement. Also, comparing W (a refractory element) and Sn (a volatile element) RSFs, we do not observe any significant difference that could imply a volatility fractionation effect correlated with their $50 \%$ condensation temperature as reported by Steenstra et al. ${ }^{27}$ Consequently, no correction for matrix effects resulting from ablation-induced evaporative and/ or melting processes has been applied.

Overall, the cross-check with metallic standards demonstrates the reliability of using NIST SRM 610 silicate glass standard as calibrator reference material for $\mathrm{Al}-\mathrm{Cu}-\mathrm{Fe}-\mathrm{Ni}$ QC analyses. We decided to use ${ }^{27} \mathrm{Al}$ as an internal standard instead of ${ }^{57} \mathrm{Fe}$ because of better counting statistics on the peak. Data reduction was performed utilizing the IOLITE 3 package, $^{28}$ following the procedure reported by Longerich et al. $^{29}$ Four reference materials were regularly analyzed as unknowns to provide quality controls, namely, NIST SRM 612, USGS BCR2G, USGS BHVO2G, and USGS GSD1. ${ }^{30}$

The analytical capability (i.e., precision and accuracy) of the instrumentation for routine analyses was reported in Petrelli et al. ${ }^{18-20}$ In detail, for the analytical conditions utilized in this study, instrumental precision is typically better than $7 \%$ for all elements. Also, Table S1 and Figure S3 report the accuracy of the analyses for the quality controls utilized in this study. For silicates, accuracy values are always better than $17 \%$, mostly $10 \%$, with few exceptions, especially at sub- $\mu \mathrm{g} / \mathrm{g}$ levels (Table S1).

\section{RESULTS}

The trace element contents of the analyzed natural quasicrystal specimens are reported in Table 2. It is important to highlight that when the signal (counts per second) was below the $3 \sigma$ detection limit filter (LOD), the content of that element is not given. However, elemental contents are shown as "<value" for those elements whose signal was above the $3 \sigma$ detection limit filter but whose uncertainty was such that $C^{\mathrm{el}}-1 \sigma<\mathrm{LOD}$, where $C^{\mathrm{el}}$ is the measured elemental abundance and $1 \sigma$ is the standard deviation of the measurement. Hence, those elemental contents are given as semiquantitative estimates, meaning they have high uncertainty and can best be interpreted as an upper limit to the concentration.

Although these reported values are only semiquantitative estimates, they are reported as the only currently available information on the presence of these elements in natural QCs. The temporal instability in the count rate that leads in some cases to large relative errors may be due to the fact that the trace elements are not uniformly distributed within the volume sampled by the laser beam $\left(\sim 5 \times 10^{5} \mu \mathrm{m}^{3}\right)$. This apparent 


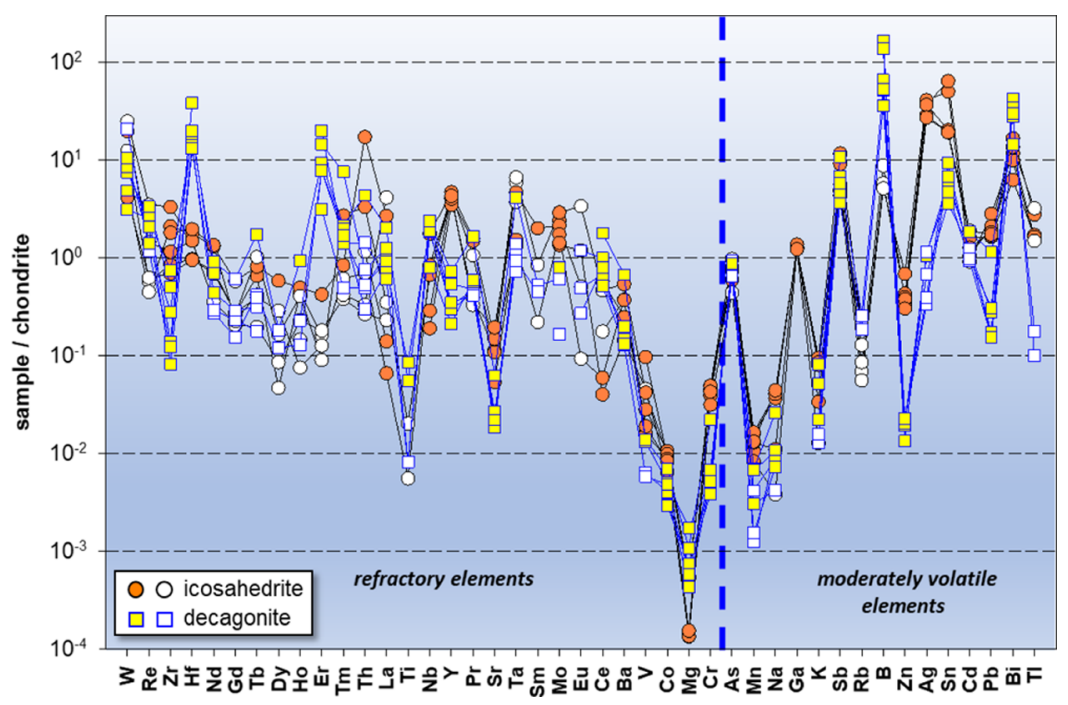

Figure 2. Chondrite-normalized ${ }^{33}$ trace element spider diagram of natural icosahedrite and decagonite, ordered from left to right with decreasing $50 \%$ condensation temperature $\left(T_{\mathrm{C}}\right)$ in a gas of solar composition at $10^{-4}$ bar. $^{32}$ Refractory $\left(T_{\mathrm{C}}=1850-1250 \mathrm{~K}\right)$ and moderately volatile $\left(T_{\mathrm{C}}=\right.$ $1250-250 \mathrm{~K}$ ) elements have been separated by a vertical dashed blue line. Both QCs have quite a unique pattern that has never been observed in other chondritic meteorites. ${ }^{34-36}$ They yield chondritic, or slightly suprachondritic, refractory element (from $\mathrm{W}$ to Ba) content followed by a strong depletion in moderately refractory elements ( $, \mathrm{Co}, \mathrm{Mg}, \mathrm{Cr}$ ) and a systematic and significant enrichment in moderately volatile elements (MVEs) from As to $\mathrm{Tl}$ (see the text for discussion). Filled and open symbols refer to elements determined at quantitative and semiquantitative levels, respectively (see the Results section of the text).

nugget effect ${ }^{31}$ is consistent with the idea that the analyzed budget of trace elements is concentrated in the 3-5 vol \% of mineral nanoparticles randomly distributed within the Khatyrka QCs, as reported by previous SEM-TEM studies $^{6,15,16}$ (see also Figure S1).

The role of nanoparticle inclusions in QCs is reflected in the time-resolved signals acquired during the ablation. This is particularly important for interpreting the light rare-earth elements in natural icosahedrite. As an example, Figure S4 shows time-resolved signals for $\mathrm{Al}, \mathrm{La}$, and $\mathrm{Ce}$ of sample NI2_02. The Al signal (Figure S4a) is reported to highlight the behavior of the internal standard, and it can be used as a proxy for well-resolved elements. The signals for La (Figure S4b) and Ce (Figure S4c) have no counts (cps) during background acquisition and detectable cps during the ablation. The cps, however, are sometimes characterized by high-energy transients of short duration (Figure S4b,c) causing large uncertainty in elemental content. In this example (NI2_02, Table 2), reporting the La result as mean and standard deviation would give $1.0 \pm 1.6 \mu \mathrm{g} / \mathrm{g}$. Evidently, the distribution of count rates over time is not Gaussian and the standard deviation is somewhat misleading. However, we determine whether to report this value as an upper limit using the $C^{\mathrm{el}}-$ $1 \sigma<\mathrm{LOD}$ criterion. In this case, therefore, La is reported as an upper limit, $<1.0 \mu \mathrm{g} / \mathrm{g}$ (Table 2). This is different from an element that is not detected. Rather, the occurrence of highenergy transients makes the counting statistics very poor, precluding a definitive measure. The source of the high-energy transient signals is also interesting. They cannot be attributed to instabilities of the analytical system as they never occurred during background acquisition. The likely source, in our opinion, is the random occurrence among the nanoparticle population included in the QCs of rare grains highly enriched in light rare-earth elements. ${ }^{5,14,16}$ Consequently, as detailed below, we will model the observed trace element signature by assuming that the budget of trace elements in these ablations is dominated by the two types of nanoparticles rather than the
QC host phases. We will show that there is a clear distinction in behavior between those elements with well-resolved stable counts (occupying abundant nanoparticle phases being ablated in statistically large numbers) and those showing transient anomalies (concentrated in rare nuggets). Moreover, the sequential elemental acquisition of a large number of elements requires cycles for the acquisition of the entire element set that are longer than the duration of the signal spike from a single nanoparticle, resulting in uncorrelated signals for elements such as La and Ce (Figure S4b,c). Although elements that are extremely enriched in a small fraction of the nanoparticles are therefore impossible to interpret, this does not preclude the interpretation of other elements, even if they are predominantly hosted in more uniformly sampled nanoparticles. Most elements yield stable signals over the full duration of ablation, implying adequate sampling of their average concentration within the ablation volume.

Trace Element Signature of QCs. A first glimpse of the trace element signature can be obtained with the help of a multielement chondrite-normalized plot (Figure 2). In this diagram, we have reported all of the elements analyzed, including those whose content is at a semiquantitative level (open symbols in Figure 2), to have a general picture of the pattern. The only exceptions are $\mathrm{Al}, \mathrm{Ni}, \mathrm{Fe}$, and $\mathrm{Cu}$, which, being major constituents of either icosahedrite $(\mathrm{Al}, \mathrm{Fe}, \mathrm{Cu})$ or decagonite $(\mathrm{Al}, \mathrm{Fe}, \mathrm{Ni}$ ), would strongly bias the pattern.

The elements are plotted, from left to right, in order of decreasing $50 \%$ condensation temperature $\left(T_{C} ;\right.$ defined as the temperature below which $50 \%$ of the original gas budget of an element is found in solid phases) in a gas of solar composition at $10^{-4}$ bar. $^{32}$ Elemental concentrations in the natural icosahedrite and decagonite are normalized to the corresponding elemental concentrations in CI chondrites. ${ }^{33}$ The patterns of the two natural QCs are quite unique compared to those of other chondritic objects. ${ }^{34-36}$ Refractory elements from $\mathrm{W}$ to Ba have moderately supra- or subchondritic values, within about 1 order of magnitude of chondritic, except $\mathrm{Ti}(<0.1 \times$ 
chondrite in both icosahedrite and decagonite $)$ and $\mathrm{Sr}(<0.06 \times$ chondrite in decagonite). Ti values are at a semiquantitative level, but this element is clearly depleted; if it approached chondritic abundance, it would have easily been resolved by the measurement. Within the general band of about 2 orders of magnitude around chondritic concentrations, there are a number of large anomalies, about 2 orders of magnitude, in chondrite-normalized ratios of refractory elements. Similar or larger anomalies in ratios of refractory elements have been observed in a few meteoritic objects (Figure S5), including a unique ultrarefractory inclusion in Murchison ${ }^{37}$ and in a class of Ca-Al-rich inclusions (CAIs) dubbed Group $\mathrm{II}^{31,35}$ we will discuss below whether these refractory objects offer models for understanding one component of the population of nanoparticle inclusions within the natural QCs (see Discussion).

Another significant difference in comparison with other chondritic objects starts from the still moderately refractory element vanadium and proceeds to the entire set of moderately volatile elements (MVEs). Both QCs yield a uniform decrease to subchondritic values of moderately refractory elements from $\mathrm{V}$ to $\mathrm{Mg}(\leq 0.001 \times$ chondrite in both NI and ND points) followed by an overall increase to suprachondritic values of MVE (B up to $160 \times$ chondrite in decagonite). The increase is neither uniform nor identical in the two QCs, with decagonite having more pronounced negative anomalies in $\mathrm{Zn}, \mathrm{Pb}$, and $\mathrm{Tl}$. Again, $\mathrm{Tl}$ content is at a semiquantitative level in decagonite (Figure 2 and Table 2) and will not be considered further. This is the first time, to the best of our knowledge, that such a large enrichment in MVE has been reported in an extraterrestrial object (Figure 2).

More details of the peculiar and unique elemental enrichment and depletion patterns in icosahedrite and decagonite can be seen by selecting and plotting characteristic elemental ratios (Figure 3). For comparison, we also plot average chondrite compositions from several sources ${ }^{34-36,38,39}$ and a set of scoriaceous cosmic spherules (SCSs) $)^{40-42}$ that have MVE enrichments smaller in magnitude but with a pattern similar to the natural QCs, albeit starting from a different primordial component.

The $x$-axes of all three panels of Figure 3 represent the fractionation of refractory elements using the ratio of a highly refractory element $\left(\mathrm{Zr}, T_{\mathrm{C}}=1722 \mathrm{~K}\right)$ to a moderately refractory element $\left(\mathrm{Cr}, T_{\mathrm{C}}=1291 \mathrm{~K}^{32}\right)$. The $y$-axes represent the fractionation of a number of $\operatorname{MVE}(\mathrm{Sb}, \mathrm{Pb}, \mathrm{Bi} ; 1250 \mathrm{~K}>$ $\left.T_{\mathrm{C}}>250 \mathrm{~K}\right)$ ratioed to moderately refractory $\mathrm{Cr}$. Note that shock recovery experiments that have synthesized icosahedral quasicrystals show that $\mathrm{Cr}$ may be incorporated in the icosahedral structure, ${ }^{10,43,44}$ so low concentrations of $\mathrm{Cr}$ in the analysis of $\mathrm{QC}$ with nanoinclusions do not reflect strong exclusion from the QC structure.

From the chondrites through the SCSs to the natural QCs, there are striking increases of 2 to 4 orders of magnitude in $\mathrm{Zr}$ / $\mathrm{Cr}, \mathrm{Sb} / \mathrm{Cr}, \mathrm{Bi} / \mathrm{Cr}$, and $\mathrm{Pb} / \mathrm{Cr}$ (Figure 3). The increase in $\mathrm{Zr}$ / $\mathrm{Cr}$ in both SCSs and QCs requires a process that fractionates refractory elements from one another, which is presumably a high-temperature process involving condensation above 1350$1300 \mathrm{~K}$. On the other hand, the increases in $\mathrm{Bi} / \mathrm{Cr}, \mathrm{Sb} / \mathrm{Cr}$, and $\mathrm{Pb} / \mathrm{Cr}$ point to an MVE-rich component that can only be incorporated into solids at low temperature.

All of the selected ratios are positively correlated, indicating that the magnitude of depletion of moderately refractory elements is somehow linked to the magnitude of enrichment in MVEs, despite the two fractionations likely occurring in
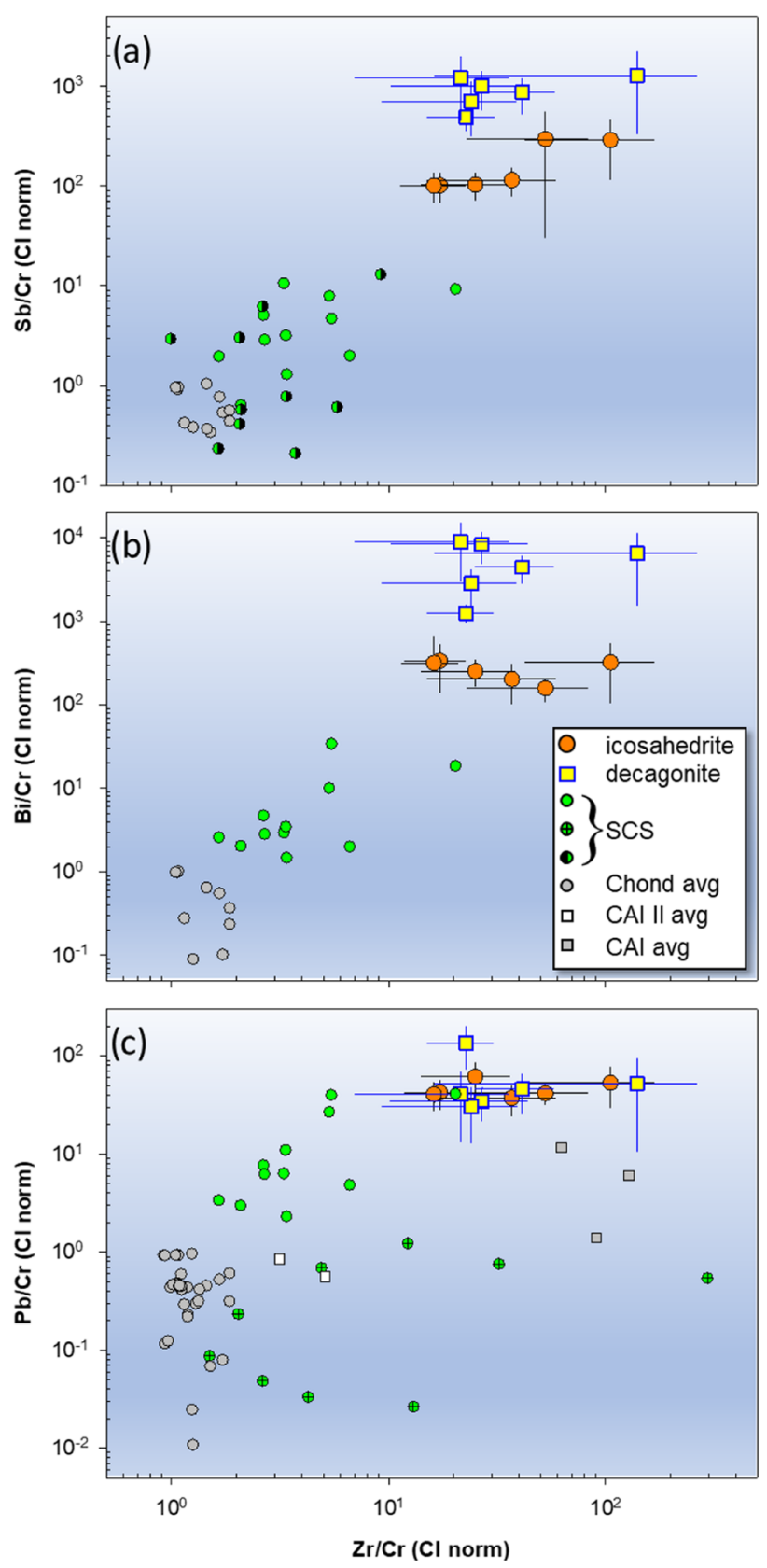

Figure 3. Chondrite-normalized ${ }^{33} \mathrm{Zr} / \mathrm{Cr}$ vs MVEs Sb (a), Bi (b), and $\mathrm{Pb}$ (c) ratioed to $\mathrm{Cr}$ (logarithmic axes). The enrichment ( $\mathrm{Bi} / \mathrm{Cr}$ up to 4 orders of magnitude) in MVEs and depletion in moderately refractory elements, such as $\mathrm{Cr}$, is clearly evident in icosahedrite and decagonite with respect to chondrites. In the three panels, we have also plotted a set of scoriaceous cosmic spherules (SCSs) that exhibit smaller enrichment in MVEs and occupy an intermediate position between chondrites and QC compositions. All of the selected ratios are positively correlated, indicating that the magnitude of depletion of moderately refractory elements is somehow linked to the magnitude of enrichment in MVEs (see the text for discussion). We note that all of the elements are at a quantitative level. Literature data sources: average chondrite compositions. ${ }^{34,36,38}$ average Group II CAI compositions; ${ }^{31,35}$ average CAI compositions; ${ }^{35}$ scoriaceous cosmic spherules (SCSs): black-green circles, ${ }^{39}$ green circles, ${ }^{41}$ and crossed green circles. $^{42}$

different processes and at different times. The correlation between the magnitude of refractory element fractionation and MVE enrichment (Figure 3) is a natural consequence of an 
admixing process. The more $\mathrm{Cr}$ is removed in the hightemperature stage, the easier it becomes to raise $\mathrm{Sb} / \mathrm{Cr}, \mathrm{Bi} / \mathrm{Cr}$, and $\mathrm{Pb} / \mathrm{Cr}$ by adding a given fraction of a low-temperature MVE-rich component.

The behavior of $\mathrm{Pb} / \mathrm{Cr}$ (Figure 3c) adds another piece to the puzzle. Unlike $\mathrm{Zr} / \mathrm{Cr}, \mathrm{Sb} / \mathrm{Cr}$, and $\mathrm{Bi} / \mathrm{Cr}$, which remain within an order of magnitude or less of CI chondrites in all of the chondrite classes, $\mathrm{Pb} / \mathrm{Cr}$ varies among chondrite classes by over 2 orders of magnitude, becoming progressively depleted from carbonaceous to ordinary to enstatite chondrites. This depletion of an MVE takes place at nearly constant $\mathrm{Zr} / \mathrm{Cr}$, implying a comparatively low-temperature volatile loss process compared to that which affected natural QCs. However, one component of chondritic objects, the $\mathrm{Ca}-\mathrm{Al}$-rich inclusions (CAIs), thought to be high-temperature condensates with subsequent histories of high-temperature evaporative processing, ${ }^{45}$ display fractionation of refractory elements (e.g., not chondritic $\mathrm{Zr} / \mathrm{Cr}$ ) as strong as the natural QCs but without as large an enrichment in MVEs (e.g., $\mathrm{Pb} / \mathrm{Cr}$ ). ${ }^{35}$ This again suggests that one step in the evolution of the natural QCs involved high-temperature condensation, able to fractionate moderately from highly refractory elements in QCs.

\section{DISCUSSION}

Scenario for Forming Natural Quasicrystals. The similarities and differences between the natural quasicrystals (QCs) and scoriaceous cosmic spherules (SCSs) are further explored in Figure 4, which plots chondrite-normalized concentrations of MVEs of varying volatility $(\mathrm{Mn}, \mathrm{Bi}$, and $\mathrm{Sb}$ ) against moderately refractory Cr. SCSs all have essentially chondritic abundances of $\mathrm{Cr}$ (as well as slightly volatile $\mathrm{Mn}$, Figure $4 \mathrm{a}$, and slightly suprachondritic highly refractory $\mathrm{Zr}$, not shown). In contrast, natural QCs have subchondritic abundances of the moderately refractory elements, with CInormalized $\mathrm{Cr}$ concentrations of $\sim 0.04$ in icosahedrite and $\sim 0.005$ in decagonite (Figure 4a). Yet, the enrichment in MVE (e.g., $\mathrm{Sb}$ and $\mathrm{Bi}$, Figure $4 \mathrm{~b}, \mathrm{c}$ ) is common to both QCs and SCSs. To the extent that depletion of and fractionation among moderately refractory elements requires high temperatures while the addition of moderately volatile elements requires low temperatures, this observation suggests that the natural QCs and SCSs probably experienced quite different high-temperature processing environments but comparatively similar lowtemperature processing environments. This general idea is illustrated in Figure 4 using schematic arrows to indicate the effects of high-temperature (red arrows) and low-temperature (blue arrows) processing steps. In Figure $4 \mathrm{a}, \mathrm{Mn}$ and $\mathrm{Cr}$ express only the high-temperature process of condensation or evaporation, experienced by the QCs but not by SCSs or bulk chondrites. The larger lever arm of the differential volatility of $\mathrm{Bi}$ and $\mathrm{Sb}$ relative to $\mathrm{Cr}$, however, allows Figure $4 \mathrm{~b}, \mathrm{c}$ to show both high- and low-temperature stages. Starting from a common CI chondritic composition, the slope of coupled depletions of moderately refractory and moderately volatile elements depends on temperature. The QCs may have experienced higher temperatures $(T>1350-1300 \mathrm{~K})$, leading to subchondritic abundances of both $\mathrm{Cr}$ (as well as $\mathrm{V}, \mathrm{Co}, \mathrm{Mg}$, Figure 2) and MVE, whereas bulk chondrite classes and possibly SCSs experienced lower temperatures (although $T>$ $1100 \mathrm{~K})$ and developed subchondritic abundances only of MVE. In a second step, an MVE-rich component was admixed into both QCs and SCSs, resulting in the observed trace element patterns.

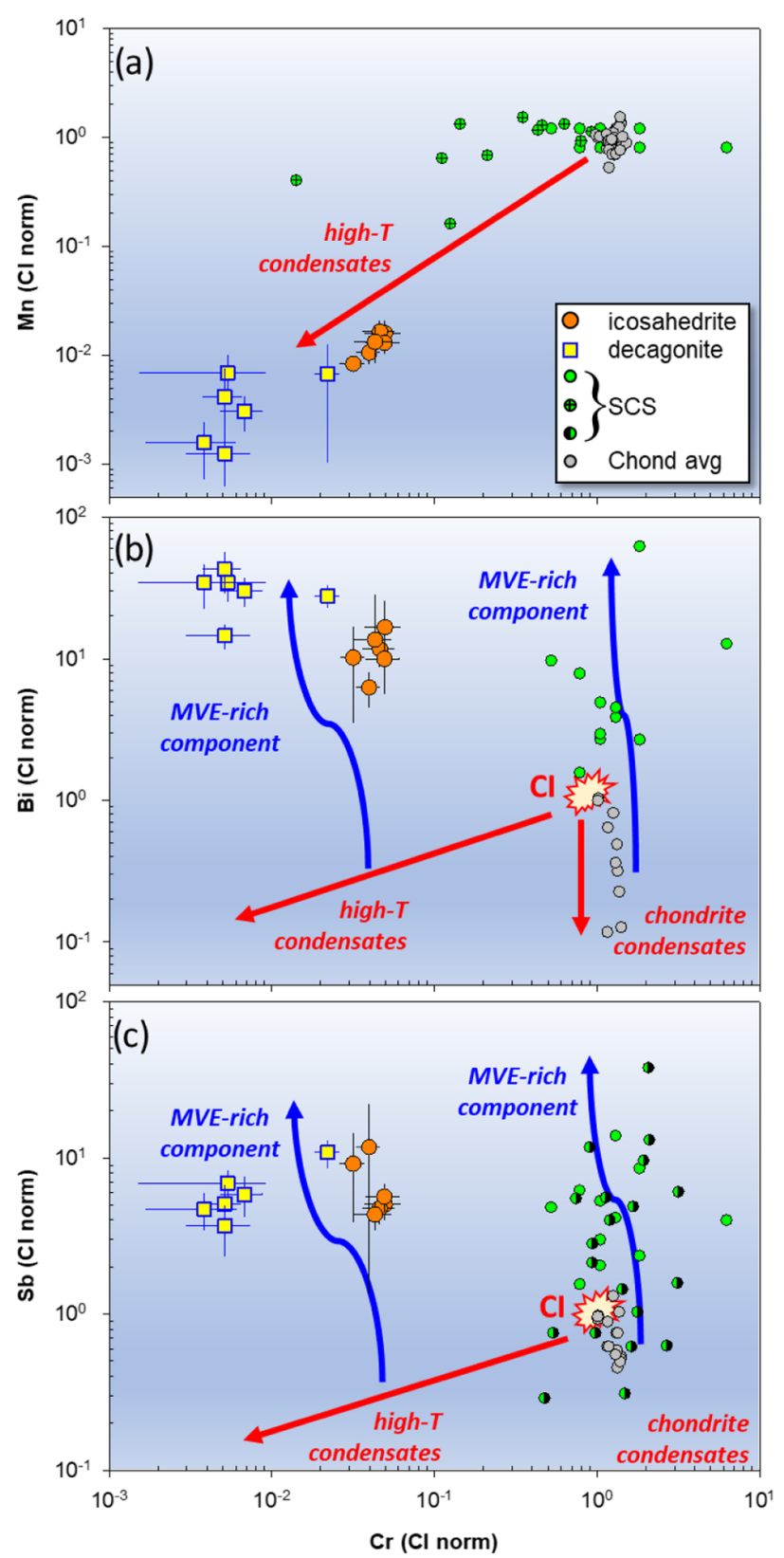

Figure 4. Chondrite-normalized ${ }^{33}$ moderately refractory $\mathrm{Cr}$ vs MVEs of varying volatility: $\mathrm{Mn}$ (a), $\mathrm{Bi}(\mathrm{b})$, and $\mathrm{Sb}$ (c) (logarithmic axes). QCs and SCS have a marked difference in moderately refractory and slightly volatile element concentration ( $\mathrm{Cr}$ and $\mathrm{Mn}$ ), whereas the enrichment in MVEs ( $\mathrm{Sb}$ and $\mathrm{Bi}$ ) is common to both QCs and SCS. This observation suggests that QCs and SCSs probably experienced quite different high-temperature processing environments as suggested by refractory element content (red arrows) but comparatively similar low-temperature processing environments as indicated by moderately volatile element content (blue arrows). The arrows in this figure are schematic; see Figure 7 and the text for an illustrative quantitative model. All $\mathrm{QC}$ analyses are at a quantitative level. Literature data sources as in Figure 3; the CI chondrite composition is highlighted.

It seems evident that the low-temperature admixture must occur after the high-temperature processing or its MVE signature would have been wiped out.

Model for the Origin of the QC Trace Element Signature. In the following section, we present a three-stage model for the origin and evolution of the high- $T$ nanoparticle 
condensates (stage I), the MVE-rich nanoparticle condensates (stage II), and the formation of the QCs that incorporated the two different types of nanoparticles (stage III). The trace element signature of the two QCs forms well-organized patterns when plotted relative to primitive carbonaceous chondrite material on a volatility-ordered diagram. The pattern in both decagonite and icosahedrite is marked by increasingly strong depletion of moderately refractory elements from $\mathrm{W}$ to Cr, with $50 \% T_{\mathrm{C}}>1250 \mathrm{~K}$ (Figure 2), followed by enrichment up to $160 \times$ chondrite in many moderately volatile elements with $50 \% T_{\mathrm{C}}<1250 \mathrm{~K}$ (Figures 2, 3, and 4). Considered together with chondrite classes and scoriaceous cosmic spherules, the natural quasicrystals appear to define a strong correlation between the magnitude of fractionation among the refractory elements (e.g., $\mathrm{Zr} / \mathrm{Cr}$ ) with the magnitude of addition of an MVE-rich component (Figures 3 and 4). This is something of a paradox in that the icosahedrite and decagonite, or rather the aggregates of materials ablated by a $110 \mu \mathrm{m}$ laser spot focused on the quasicrystalline domains, appear to have been affected by two sets of processes that occurred at different temperatures and so presumably in different environments and at different times within the solar nebula. A successful theory incorporating both the high- and low-temperature processing in the $\mathrm{CV}$ formation region may offer significant insight into the evolution of the region of the solar protoplanetary disk where the processes took place. Our proposed model can be decomposed into three successive stages.

First Stage: Reservoir \#1, Inner Solar System. The first stage is either similar or complementary to the processing that formed CAIs. Condensation from solar gas initially forms ultrarefractory condensates consisting of corundum, hibonite, grossite, and transition-metal alloys. ${ }^{32,46,47}$ Either termination of this process well above the $50 \%$ condensation temperature of moderately refractory elements or an evaporation stage involving reheating above $T_{\mathrm{C}}$ of these elements results in solid material whose refractory element pattern is fractionated (e.g., Figure S5). This material has suprachondritic $\mathrm{Zr} / \mathrm{Cr}$ (Figure 3) strong depletion in MVE (blue arrows, Figure 4) and likely extremely low concentrations (dominated perhaps by adsorption onto grains) of highly volatile elements.

We propose that these high- $\mathrm{T}$ condensates constitute some fraction of the nanoparticles in the two QCs. The occurrence of nanoparticles of complementary high-T condensates in QCs can be better appreciated in Figure 5, where Tm/Er anomalies are plotted versus $\mathrm{Zr} / \mathrm{Cr}$ and $\mathrm{Nd} / \mathrm{Er}$. Tm and $\mathrm{Er}$ are neighboring lanthanides whose fractionation is generally controlled by the general trend of ionic radius, except that high-temperature evaporation and condensation yield anomalous fractionation of Er. ${ }^{31}$ Figure 5a shows that the positive and negative anomalies in $\mathrm{Tm} / \mathrm{Er}$ in decagonite and icosahedrite (albeit on a reduced data set because some samples have semiquantitative estimates of $\mathrm{Tm}, \mathrm{Er}$, or $\mathrm{Nd}$; Table 2), resemble those in Group II CAIs and in ultrarefractory inclusions in Murchison. The QCs are apparently sampling, at the nanoscale, anomalies similar to those caused at the microscale in Allende and Murchison by the heterogeneous distribution of refractory inclusions that host a large part of their refractory element budgets. ${ }^{35}$ Group II CAIs have suprachondritic $\mathrm{Tm} / \mathrm{Er}, \mathrm{Nd} / \mathrm{Er}$, and $\mathrm{Zr} / \mathrm{Cr}$ (Figure $5 \mathrm{a}, \mathrm{b})$. Their $\mathrm{Tm} / \mathrm{Er}$ and $\mathrm{Nd} / \mathrm{Er}$ signature is complementary to sequestration of excess $\mathrm{Er}$ in an ultrarefractory component, possibly hibonite, ${ }^{48}$ such as that documented in the ultrarefractory inclusion in Murchison. ${ }^{37}$ This is a different signal
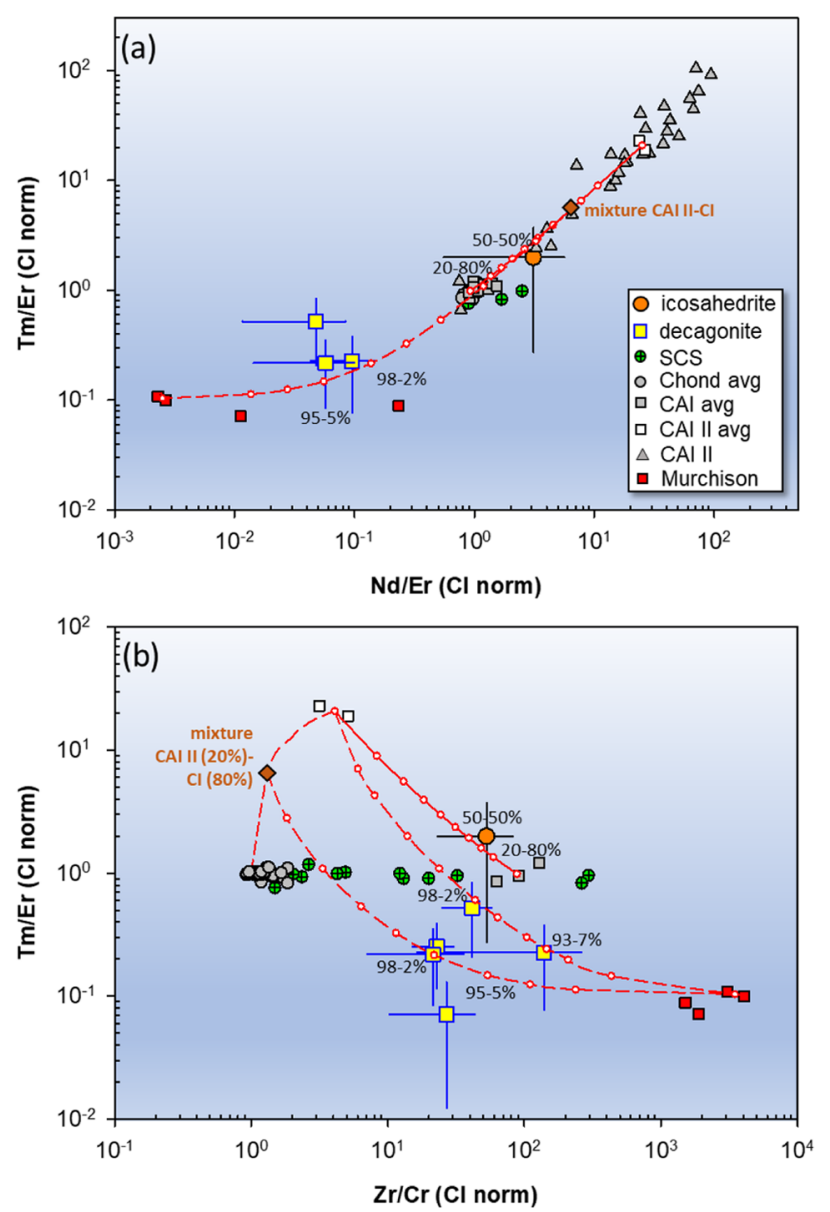

Figure 5. Chondrite-normalized ${ }^{33}$ (a) $\mathrm{Tm} / \mathrm{Er}$ vs $\mathrm{Nd} / \mathrm{Er}$ (b) and $\mathrm{Zr}$ / $\mathrm{Cr}$ (logarithmic axes). These two panels are suggestive of incorporation of different and complementary mixtures of high- $T$ condensates resembling composites of Group II CAIs $(20-50 \%)$ and normal CAIs $(80-50 \%)$ in icosahedrite (solid red line), whereas decagonite (dashed red lines) appears to contain a composite resembling a small percentage of the ultrarefractory inclusions in Murchison (2-7\%) with either Group II CAIs (93-98\%) or a mixture (95-98\%) between Group II CAIs and up to $80 \%$ normal CI chondrites. The compositions and percentages of all mixtures (small open red circles) are reported in Table S2, whereas only the relevant composite percentages are indicated in the two panels. The mixing line between Murchison inclusions and Group II CAIs is not shown in panel (a) for the sake of clarity. Only QC analyses at a quantitative level have been reported. Literature data sources as in Figure 3 plus Group II CAIs ${ }^{50}$ and ultrarefractory inclusions of the Murchison meteorite. ${ }^{37}$

from that seen in $\mathrm{Zr} / \mathrm{Cr}$, where all of these objects have variably suprachondritic $\mathrm{Zr} / \mathrm{Cr}$ (Figure $5 \mathrm{~b}$ ) because all of the processing involved in fractionating hibonite from other refractory phases is taking place well above the $50 \% T_{C}$ of Cr. ${ }^{31,49,50}$ Incidentally, the negative $\mathrm{Ti}$ (semiquantitative value but clearly depleted) and $\mathrm{Sr}$ anomalies observed in QCs (Figure 2$)$ could indicate the absence of titanates [ $(\mathrm{Ca}, \mathrm{Sr})$ $\left.\mathrm{TiO}_{3}\right]$ in these condensates, which implies condensation temperature in excess of about $1570 \mathrm{~K},{ }^{32,46,47}$ consistent with the condensation temperature of hibonite at some $1740 \mathrm{~K}^{50}$

Quantitative Model of the First Stage. Group II CAIs and the Murchison inclusions may not be perfect analogues for the refractory nanoparticles in the Khatyrka QCs, and a wide variety of refractory element patterns could be possible during 
high- $T$ condensation from the solar nebula. ${ }^{37}$ However, they provide an illustrative example of the material that was processed in a high- $T$ nebular environment to create complementary enrichments and depletion of highly refractory elements. Bearing these limitations in mind, we construct a model that assumes that the QCs themselves are barren in the trace elements considered, with the measured inventory hosted entirely in the refractory fraction of the enclosed nanoparticles. The ingredients available to form these nanoparticles are represented by the following putative end-member proxies (Table S2): (1) the average of the two Murchison inclusions with the most extreme $\mathrm{Zr} / \mathrm{Cr}^{37}$ (2) the average of Group II CAIs, ${ }^{31,35}$ (3) the average of other CAIs, ${ }^{35}$ and (4) CI chondrites. $^{33}$

The mixing results (Table S2), reported in the two panels of Figure 5, are suggestive of incorporation of two types of complementary refractory inclusions in each of the QCs. The nanoparticles in icosahedrite can be modeled as a binary mixture of high- $T$ condensates consisting entirely of Group II CAIs and other CAIs, with the percentage of Group II CAIs in the mix somewhere between 20 and $50 \%$. On the other hand, the nanoparticles in decagonite mix toward a non-CAI component that we model using the ultrarefractory inclusions in Murchison. A proportion between 2 and $7 \%$ of the Murchison inclusions, when mixed with a component varying between pure Group II CAIs and an admixture of Group II CAIs with up to $80 \%$ CI chondrite (Table S2), encompasses the range of decagonite analyses in the examined refractory element ratios.

In terms of absolute amount (Table S2), 3\% of these high-T composites, in agreement with the occurrence of $3-5 \%$ silicate/oxide inclusions within $\mathrm{QCs},{ }^{6,15,16}$ reproduce the patterns observed in QCs (Figure 6). Keeping in mind that these modeled composites are only proxies for the actual refractory condensates, the model shows that both the absolute

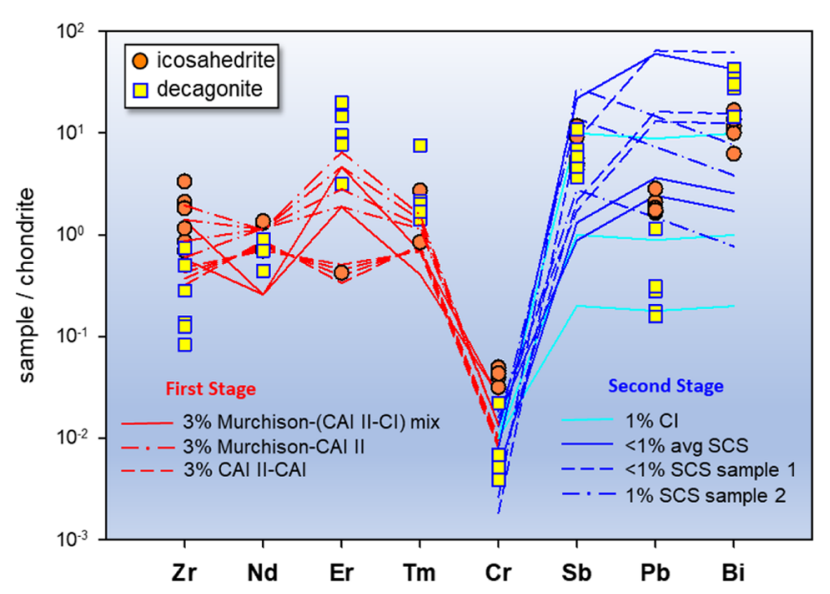

Figure 6. Chondrite-normalized ${ }^{33}$ trace element content of the modeled two-stage formation of nanoparticles enclosed in QCs. The first stage is focused on reproducing $\mathrm{Zr} / \mathrm{Cr}, \mathrm{Tm} / \mathrm{Er}$, and $\mathrm{Nd} / \mathrm{Er}$ of QCs (Figure 5) by mixing composites of different proxies for high- $T$ condensates with $\mathrm{CI}$ chondrite material (Table S2). The second stage is focused on reproducing $\mathrm{Sb} / \mathrm{Cr}, \mathrm{Bi} / \mathrm{Cr}$, and $\mathrm{Pb} / \mathrm{Cr}$ of $\mathrm{QCs}$ based upon MVE-rich vapor condensation from early object collisions (Table S3). Negative $\mathrm{Pb}$ and $\mathrm{Zn}$ anomalies (Figure 2) imply an additional stage of sulfide segregation. The calculated total amount of nanoparticles in QCs (first stage and second stage) is $\leq 4 \%$ (Tables S2 and S3), in agreement with previous independent estimates. ${ }^{6,15,16}$ All QC analyses are at a quantitative level. concentrations and the ratios of refractory elements observed in natural QCs can be reconciled with reasonable densities of components known to exist in carbonaceous chondrites.

Figure 5 also shows data on $\mathrm{SCS}^{42}$ that plot with normal CAIs and bulk chondrite in $\mathrm{Tm} / \mathrm{Er}$ and $\mathrm{Nd} / \mathrm{Er}$; we will invoke SCS-like materials below as the carrier of the MVE signature, but they were not processed at sufficiently high temperature to be carriers of the anomalies in highly refractory elements.

Second Stage: Reservoir \#2, MVE-Rich Component. The formation of MVE-rich components and their incorporation into inner solar system material is controversial, and there is presently no consensus on a unique scenario.

The MVE-rich component could be ascribed to the gas phase of the interstellar medium, which forms the complementary reservoir to elements incorporated into solid dust, which in turn are represented in chondritic solids. Refractory elements depleted in the gas phase of the interstellar medium are enriched in chondrites, whereas the opposite is true for MVE. The composition of interstellar gas has been inferred from absorption-line observations of the $\zeta$ Ophiuchi Cool Gas, $\xi$ Persei Cool Gas, and Galactic Cold Cloud. ${ }^{51-55}$ The removal of refractory elements from the gas phase will naturally leave a complementary enrichment of volatile elements simply by mass balance. However, the suprachondritic abundances of some MVEs up to $160 \times$ chondrite (Figure 2) are too large an enrichment to be obtained by removal of refractory elements from a region with near-solar metallicity and relative abundances of the elements, according to the interstellar medium observations reported in the aforementioned papers. Furthermore, this source requires delivery of the interstellar material to the disk by infall at an appropriate stage of disk evolution, without reheating to the point where the MVEs are lost back to the gas phase.

Another possible source of an MVE-enriched component within the protoplanetary disk itself could be the residual nebular gas during the later, low-temperature stage of nebular evolution just before the $\mathrm{T}$ Tauri stage where the remaining gas is removed by the solar wind. The capture of such volatileenriched material into low-temperature condensates has been suggested as the origin of the mysterite dark clasts in the $\mathrm{H} 6$ chondrite Supuhee. ${ }^{5,57}$ These authors suggested that mysterite was a late, low-temperature condensate from the solar nebula that incorporated MVE left behind after condensation of the components of earlier generations of chondrites. A similar explanation was offered by Ganapathy and Larimer ${ }^{58}$ to explain their observation of MVE enrichment in the enstatite chondrite Abee. Note that if transport processes such as Xwinds ${ }^{59}$ were delivering material from different semimajor axes within the nebula, then different locations within the nebula rather than different stages of evolution at a given location might be invoked to explain the mixing of multiple components with different condensation temperatures.

Finally, the MVE-rich component could have condensed from volatile-enriched vapor produced during collisions in the solar protoplanetary disk. ${ }^{60-62}$ Collisions among early objects grew progressively more energetic and eventually began to cross the thresholds for incipient melting, complete melting, incipient vaporization, and ultimately large-scale vaporization of silicates. ${ }^{63,64}$ Remarkably, the experimental work of Norris and Wood ${ }^{61}$ demonstrated that MVEs are strongly fractionated into vapor during high-energy collisions and that lower oxygen fugacity promotes increasingly volatile behavior of MVE. This is notable because the QCs are found in an object with a 
unique oxidation state history. The incorporation of an MVEenriched component that originated from collision-induced partial vaporization may therefore offer a new constraint on the $\mathrm{fO}_{2}$ evolution responsible for the formation of Khatyrka's distinctive metallic phases.

An MVE-rich component that was present in the inner solar system from $\sim 1$ to at least $4 \mathrm{Myr}$ after the time of CAI formation has been associated with a decrease in oxygen fugacity in late nebular conditions. ${ }^{65}$ The $\mathrm{Mn} / \mathrm{Na}$ ratio of solar system objects functions as an effective proxy for the prevailing $\mathrm{fO}_{2}$ conditions during gas/solid interactions: high $f \mathrm{O}_{2}$ renders $\mathrm{Mn}$ more refractory and yields solids with high $\mathrm{Mn} / \mathrm{Na}$ ratio, whereas low $\mathrm{fO}_{2}$ has the opposite effect. Notably, the $\mathrm{Mn} / \mathrm{Na}$ ratios of the two QCs (on average 0.34 in icosahedrite and 0.15 in decagonite) are among the lowest values recorded so far in any extraterrestrial object (Figure 3 in ref 65). The extremely low $\mathrm{Mn} / \mathrm{Na}$ of $\mathrm{QCs}$ is consistent with the very reducing conditions needed to form metallic $\mathrm{Al}$. In the current context, the efficient transfer of MVEs into vapor under reducing conditions ${ }^{61}$ favors the hypothesis that the volatile component incorporated in the QCs condensed from the vapor formed by a collision during the protoplanetary accretionary stage.

Quantitative Model of the Second Stage. There are many uncertainties in constructing a model for the MVE enrichment, but we propose an approach to constraining this process using the results of Norris and Wood at $f \mathrm{O}_{2}=10^{-13}$ bars and 1300 ${ }^{\circ} \mathrm{C} .{ }^{61}$ The results of these experiments were reported as volatility factors for a number of MVEs, but the evaporated mass fraction $(F)$ was not reported, precluding direct estimates of partition coefficients. We estimated vapor/liquid partition coefficients for each element $\left(D^{i}\right)$ by analytical inversion of the Rayleigh fractional evaporation equation with an unknown value of $F$

$$
\frac{1}{D^{i}}=1+\frac{\ln \frac{C_{s}^{i}}{C_{o}^{i}}}{\ln (1-F)}
$$

where $C_{\mathrm{s}}^{i}$ and $C_{\mathrm{o}}^{i}$ are the concentrations of element $i(\mathrm{Sb}, \mathrm{Bi}$, $\mathrm{Pb}$ ) in the residue and in the starting material of the experiments of Norris and Wood, respectively (extended data, Table 2), ${ }^{61}$ and we consider $F$ values of 5, 1, and $0.1 \%$ (Table S3). $D^{\mathrm{Cr}}$ has been assumed equal to unity on the basis of the results of Norris and Wood. ${ }^{61}$ We then used the set of calculated $D^{i}$ to model aggregated fractional vapor formed by various extents of Rayleigh evaporation of CI chondrite, ${ }^{33}$ the average SCS, and two extreme SCS samples ${ }^{41}$ (Table S3).

The results are illustrated in the two panels of Figure 7. Figure $7 \mathrm{a}, \mathrm{Sb} / \mathrm{Cr}$ vs $\mathrm{Bi} / \mathrm{Cr}$, demonstrates that impact-induced partial vaporization of the modeled starting materials could have created a reservoir enriched in MVE that, upon condensing, would be a plausible source for the MVE-rich component subsequently incorporated in the QCs. The absolute amount of the MVE-rich component necessary to roughly reproduce the pattern observed in QCs ranges from 1 to $0.1 \%$ (Table S3 and Figure 6), which, added to the refractory nanoparticles from the first stage, yields $\leq 4 \%$ total nanoparticles, consistent with the $3-5 \%$ observation of nanoparticle density via electron microscopy. $6,15,16$

The vaporization model predicts, however, the wrong sign of $\mathrm{Pb} / \mathrm{Cr}$ anomalies (Figure $7 \mathrm{~b}$ ) and implies $\mathrm{Pb}$ contents (Figure 6) derived from the MVE-rich component that are higher than the values observed in QCs. Considered together with the
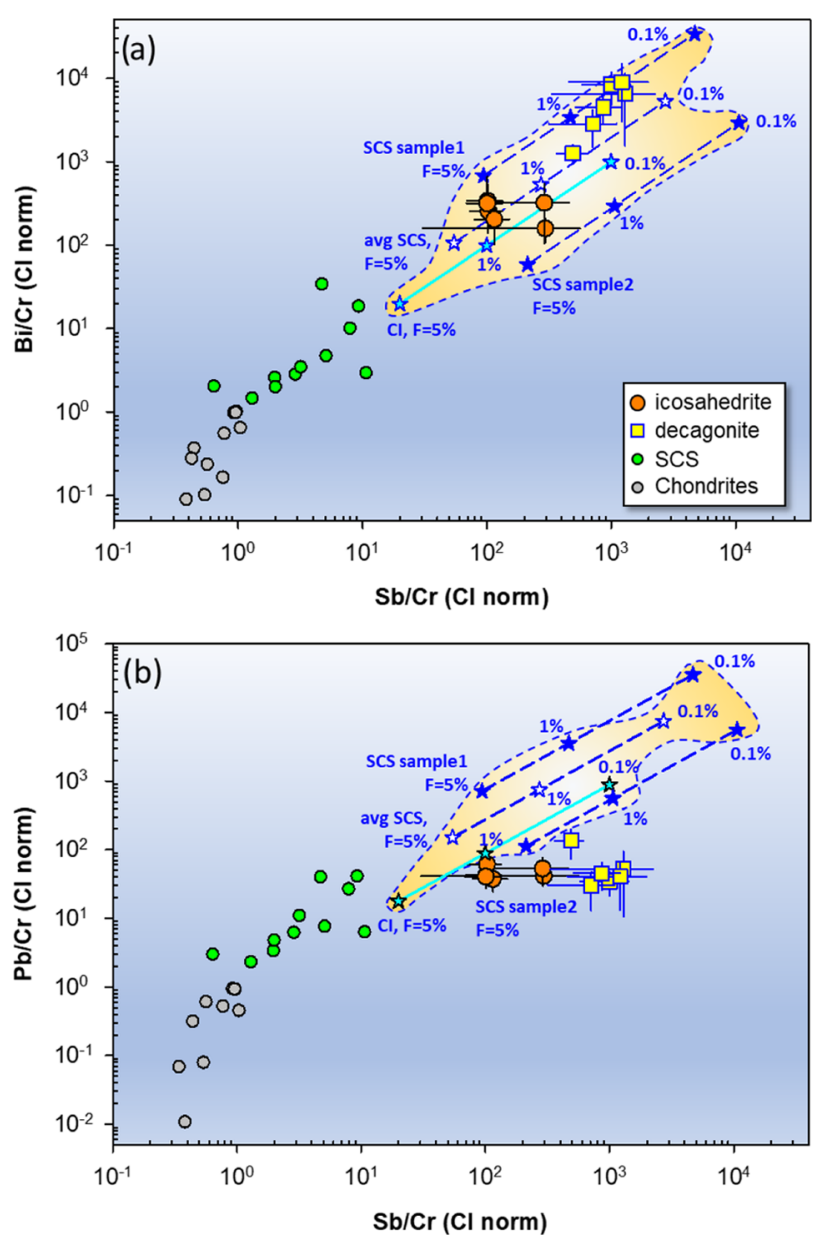

Figure 7. Chondrite-normalized ${ }^{33}$ (a) $\mathrm{Sb} / \mathrm{Cr}$ vs $\mathrm{Bi} / \mathrm{Cr}$ and (B) $\mathrm{Sb} / \mathrm{Cr}$ vs $\mathrm{Pb} / \mathrm{Cr}$ (logarithmic axes). The enrichment in MVEs in the QC domains is modeled using aggregated Rayleigh fractional evaporation and partition coefficients estimated from the experimental results of Norris and Wood ${ }^{61}$ as described in the text, using as starting materials CI chondrite, ${ }^{33}$ average SCS, and two extreme SCS samples ${ }^{41}$ (Table S3). The model shows that condensation of an MVE-enriched vapor could create the $\mathrm{Sb} / \mathrm{Cr}$ and $\mathrm{Bi} / \mathrm{Cr}$ signature of the QCs. However, low $\mathrm{Pb} / \mathrm{Cr}$ (and $\mathrm{Zn}$ ) in the QCs points to an additional effect, perhaps segregation of sulfides from the vapor phase (see the text). Percentages refer to the evaporated mass fraction F. All QC analyses are at a quantitative level. Literature data sources as in Figure 3.

prominent negative $\mathrm{Zn}$ anomalies (Figure 2), the behavior of $\mathrm{Pb}$ could be explained by condensation and segregation of a sulfide phase from the vapor before condensation of the MVErich nanoparticles that would subsequently become entrapped within QCs.

Although we illustrate the formation of the MVE-enriched component of the QCs with a single-stage evaporation process, one could just as well envision multiple collisions and other more elaborate protracted processes. In fact, the SCS starting material (Figure 7) might represent an example of volatileenriched material from a previous collision.

Third Stage: Formation of QCs. Although the trace element concentrations reported here were measured by ablating material that appears, at the microscale, to be homogeneous single-phase QCs, it seems very unlikely that QCs themselves condensed as solids from the gas of the solar nebula. Volatility control fails to explain the origin and ratios of the major constituents of the QCs, icosahedrite $\left(\mathrm{Al}_{63} \mathrm{Cu}_{24} \mathrm{Fe}_{13}\right)$ and 
decagonite $\left(\mathrm{Al}_{71} \mathrm{Ni}_{24} \mathrm{Fe}_{5}\right)$. Moreover, high-temperature condensates of the solar gas all contain trivalent $\mathrm{Al}$ (e.g., corundum, hibonite, grossite); thermodynamic data appear to forbid the presence of metallic aluminum in equilibrium with the solar nebula. Thus, $\mathrm{Al}, \mathrm{Cu}, \mathrm{Fe}$, and $\mathrm{Ni}$ incorporation was likely not controlled by gas/solid partitioning. To the extent that the observed trace element patterns are indeed well explained by gas/solid fractionation processes, i.e., volatility control, the most likely explanation is that the QC domains analyzed are heterogenous at scales much smaller than the laser spot $(110 \mu \mathrm{m})$. The trace elements may be present in lattice defects or as nanoparticles of cosmic dust. Heterogeneities of these types have already been noted in previous TEM studies of Khatyrka fragments. ${ }^{15,16}$ We must therefore consider the likelihood that we are here discussing the origin and evolution of dust incorporated into QCs rather than the formation of the QCs as such.

Both QCs record the admixture of at least two different components whose elemental fractionations appear to represent different regions or different stages of the solar nebula. It has been extensively documented that Khatyrka experienced a multistage collision history ${ }^{6,7}$ and that the QCs themselves are likely the result of impact-induced processing of reduced metal precursors. ${ }^{10,43,44}$ Although the impact intensity associated with QC formation is much lower than that needed for efficient vapor production, impacts are associated with highly heterogeneous variations in shock intensity both at small scale due to target material variations (e.g., porosity) and at large scale due to distance from the impact point. Nevertheless, the proposal that MVE-enriched condensates formed out of impact-induced vapor and were then present in intimate contact with the solid metallic precursors of the QCs reinforces the multistage impact history already demonstrated for the Khatyrka meteorite. ${ }^{6-8,10,42,44}$

In summary, the Khatyrka parent body is a $\mathrm{CV}$ chondrite consisting of clasts of different origins accreted together during a complex multistage sequence of collision events ${ }^{6-8,10}$ that brought together all of the chemical ingredients to form the QCs: $\mathrm{Al}, \mathrm{Fe}, \mathrm{Ni}, \mathrm{Cu}$, and both high- and low- $\mathrm{T}$ components that conveyed to QCs their unique trace element signature. The nucleation of QCs required $P>5 \mathrm{GPa}$ (indicated by stishovite and ringwoodite inclusions in some icosahedrite grains $^{6,15}$ ), $T>1700 \mathrm{~K}$ (suggested by melting textures in some icosahedrite/ decagonite grains ${ }^{7}$ ), and low $\mathrm{fO}_{2}$ (to reduce trivalent aluminum to metallic aluminum).

The formation of QCs must have occurred during a modestsized short-lived collision ${ }^{10,66}$ following the much more energetic event that mobilized the MVE-rich component. Incidentally, extreme reduction conditions and high temperatures were suggested, by Essene and Fisher ${ }^{69}$ in their pioneering study on glassy fulgurite, to occur as a result of electrical discharges (i.e., lightning strikes) in the solar nebula following impacts among early objects. Thus, collisions (high $P$ and $T$ ), perhaps aided by electrical discharge (high $T$ and low $\left.f \mathrm{O}_{2}\right)$, ${ }^{68}$ may have provided the necessary environment for the formation of liquid metal, as suggested by the observed melting textures, ${ }^{7}$ in which QC nucleation was followed by QC domain growth that overran and incorporated nanoparticles of both components, resulting in the unique trace element signature of the QC domains (Figures 2-5 and 7). Remarkably, the formation of cupalite at $T=1700 \mathrm{~K}$ occurs at $\mathrm{fO}_{2}$ of $10^{-14}$ $10^{-13}$ bars (extrapolated from Bindi et al.), ${ }^{15}$ suggesting that all of the reduced metallic phases in Khatyrka (not just the QCs) may be attributable to the joint effects of the planetesimal collision and electrical discharge.

\section{ASSOCIATED CONTENT}

\section{Supporting Information}

The Supporting Information is available free of charge at https://pubs.acs.org/doi/10.1021/acsearthspacechem.1c00004.

Nanometric "finger" of corundum penetrating icosahedrite (Figure S1); Relative Sensitivity Factors (Figure S2); quality control analyses of reference standards (Figure S3); high energy transients during ablations (Figure S4); chondrite normalized trace elements in refractory inclusions of Murchison meteorite, Group II CAIs, and other CAIs (Figure S5); trace element analyses of reference standards (Table S1); end member proxies and trace element content of the mixing process (Table S2); starting material, partition coefficients, and trace element content at different aggregated vapor mass fractions (Table S3); note on synthetic vs natural QCs; reflected light images of synthetic QCs (Figure S6); trace element content of natural vs synthetic QCs (Figure S7); electron microprobe analyses of synthetic QCs (Table S4); trace element analyses of synthetic QCs (Table S5) (PDF)

\section{AUTHOR INFORMATION}

\section{Corresponding Author}

Luca Bindi - Dipartimento di Scienze della Terra, Università degli Studi di Firenze, I-50121 Firenze, Italy; CNR-Istituto di Geoscienze e Georisorse, Sezione di Firenze, I-50121 Firenze, Italy; orcid.org/0000-0003-1168-7306;

Email: luca.bindi@unifi.it

\section{Authors}

Simone Tommasini - Dipartimento di Scienze della Terra, Università degli Studi di Firenze, I-50121 Firenze, Italy

Maurizio Petrelli - Dipartimento di Fisica e Geologia, Università degli Studi di Perugia, I-06123 Perugia, Italy; INFN, section of Perugia, Perugia I-06123, Italy; (1) orcid.org/0000-0001-6956-4742

Paul D. Asimow - Division of Geological and Planetary Sciences, California Institute of Technology, Pasadena, California 91125, United States

Paul J. Steinhardt - Department of Physics, Princeton University, Princeton, New Jersey 08544, United States

Complete contact information is available at:

https://pubs.acs.org/10.1021/acsearthspacechem.1c00004

\section{Author Contributions}

L.B. designed the research and led the scientific team; M.P. obtained the trace element data; S.T., L.B., P.D.A, and P.J.S. wrote the paper; all authors discussed and commented on the results and gave approval to the final version of the manuscript.

\section{Funding}

The research was funded by MIUR-PRIN2017, project "TEOREM deciphering geological processes using Terrestrial and Extraterrestrial ORE Minerals", prot. 2017AK8C32 (PI: Luca Bindi).

\section{Notes}

The authors declare no competing financial interest. 


\section{ACKNOWLEDGMENTS}

We thank Timothy Eisele (Michigan Tech) and Paul Huysmans (Quality Manager at the KBM Affilips B.V. alloy corporation) for expert advice on the use of $\mathrm{Al} \mathrm{Cu}$ alloys in industrial applications and Tom Tyner, lead chemistry advisor on Reagents for the American Chemical Society, and John Elfers, Thermo Fisher Scientific, for sharing their expertise on the Devarda Alloy. We also thank M. Humayun, C. Lin, and G.J. MacPherson for their unpublished results from an earlier trace element analysis at a lower resolution, which placed useful upper bounds and motivated the improved analysis presented in this paper. We thank four anonymous reviewers for their comments and constructive criticism, which led to a substantially improved paper. The editorial handling of Eric Herbst was greatly appreciated.

\section{REFERENCES}

(1) MacPherson, G. J.; Andronicos, C. L.; Bindi, L.; Distler, V. V.; Eddy, M. P.; Eiler, J. M.; Guan, Y.; Hollister, L. S.; Kostin, A.; Kryachko, V.; Steinhardt, W. M.; Yudovskaya, M.; Steinhardt, P. J. Khatyrka, a new CV3 find from the Koryak Mountains, Eastern Russia. Meteorit. Planet. Sci. 2013, 48, 1499-1514.

(2) Levine, D.; Steinhardt, P. J. Quasicrystals: A New Class of Ordered Structures. Phys. Rev. Lett. 1984, 53, 2477-2480.

(3) Shechtman, D.; Blech, I.; Gratias, D.; Cahn, J. Metallic phase with long-range orientational order and no translational symmetry. Phys. Rev. Lett. 1984, 53, 1951-1954.

(4) Ivanova, M. A.; Lorenz, C. A.; Borisovskiy, S. E.; Burmistrov, A. A.; Korost, D. V.; Korochantsev, A. V.; Logunova, M. N.; Shornikov, S. I.; Petaev, M. I. Composition and origin of holotype $\mathrm{Al}-\mathrm{Cu}-\mathrm{Zn}$ minerals in relation to quasicrystals in the Khatyrka meteorite. Meteorit. Planet. Sci. 2017, 52, 869-883.

(5) Andronicos, C.; Bindi, L.; Distler, V. V.; Hollister, L. S.; Lin, C.; MacPherson, G. J.; Steinhardt, P. J.; Yudovskaya, M. Comment on "Composition and origin of holotype $\mathrm{Al}-\mathrm{Cu}-\mathrm{Zn}$ minerals in relation to quasicrystals in the Khatyrka meteorite” by M. Ivanova et al. (2017). Meteorit. Planet. Sci. 2018, 53, 2430-2440.

(6) Hollister, L. S.; Bindi, L.; Yao, N.; Poirier, G. R.; Andronicos, C. L.; MacPherson, G. J.; Lin, C.; Distler, V. V.; Eddy, M. P.; Kostin, A.; Kryachko, V.; Steinhardt, W. M.; Yudovskaya, M.; Eiler, J. M.; Guan, Y.; Clarke, J. J.; Steinhardt, P. J. Impact-induced shock and the formation of natural quasicrystals in the early solar system. Nat. Commun. 2014, 5, No. 3040.

(7) Lin, C.; Hollister, L. S.; MacPherson, G. J.; Bindi, L.; Ma, C.; Andronicos, C. L.; Steinhardt, P. J. Evidence of cross-cutting and redox reaction in Khatyrka meteorite reveals metallic-Al minerals formed in outer space. Sci. Rep. 2017, 7, No. 1637.

(8) Meier, M. M. M.; Bindi, L.; Heck, P. R.; Neander, A. I.; Spring, N. H.; Riebe, E. I.; Maden, C.; Baur, H.; Steinhardt, P. J.; Wieler, W.; Busemann, H. Cosmic history and a candidate parent asteroid for the quasicrystal-bearing meteorite Khatyrka. Earth Planet. Sci. Lett. 2018, 490, 122-131.

(9) Suttle, M. D.; Twegar, K.; Nava, J.; Spiess, R.; Spratt, J.; Campanale, F.; Folco, L. A unique CO-like micrometeorite hosting an exotic Al-Cu-Fe-bearing assemblage - close affinities with the Khatyrka meteorite. Sci. Rep. 2019, 9, No. 12426.

(10) Asimow, P. D.; Lin, C.; Bindi, L.; Ma, C.; Tschauner, O.; Hollister, L. S.; Steinhardt, P. J. Shock synthesis of quasicrystals with implications for their origin in asteroid collisions. Proc. Natl. Acad. Sci. U.S.A. 2016, 113, 7077-7081.

(11) Bindi, L.; Steinhardt, P. J.; Yao, N.; Lu, P. J. Natural Quasicrystals. Science 2009, 324, 1306-1309.

(12) Bindi, L.; Steinhardt, P. J.; Yao, N.; Lu, P. J. Icosahedrite, Al63Cu24Fe13, the first natural quasicrystal. Am. Mineral. 2011, 96, 928-931.

(13) Bindi, L.; Yao, N.; Lin, C.; Hollister, L. S.; Andronicos, C. L.; Distler, V. V.; Eddy, M. P.; Kostin, A.; Kryachko, V.; MacPherson, G.
J.; Steinhardt, W. M.; Yudovskaya, M.; Steinhardt, P. J. Natural quasicrystal with decagonal symmetry. Sci. Rep. 2015, 5, No. 9111.

(14) Bindi, L.; Yao, N.; Lin, C.; Hollister, L. S.; Andronicos, C. L.; Distler, V. V.; Eddy, M. P.; Kostin, A.; Kryachko, V.; MacPherson, G. J.; Steinhardt, W. M.; Yudovskaya, M.; Steinhardt, P. J. Decagonite, Al71Ni24Fe5, a quasicrystal with decagonal symmetry from the Khatyrka CV3 carbonaceous chondrite. Am. Mineral. 2015, 100, $2340-2343$.

(15) Bindi, L.; Eiler, J.; Guan, Y.; Hollister, L. S.; MacPherson, G. J.; Steinhardt, P. J.; Yao, N. Evidence for the extraterrestrial origin of a natural quasicrystal. Proc. Natl. Acad. Sci. U.S.A. 2012, 109, 13961401.

(16) Steinhardt, P. J.; Bindi, L. In search of natural quasicrystals. Rep. Prog. Phys. 2012, 75, 092601-092611.

(17) Bindi, L.; Steinhardt, P. J. How impossible crystal came to Earth: A short history. Rocks Mineral. 2018, 93, 50-57.

(18) Petrelli, M.; Caricchi, L.; Ulmer, P. Application of high spatial resolution laser ablation ICP-MS to crystal-melt trace element partition coefficient determination. Geostand. Geoanal. Res. 2007, $31,13-25$.

(19) Petrelli, M.; Perugini, D.; Alagna, K. E. K. E.; Poli, G.; Peccerillo, A. Spatially resolved and bulk trace element analysis by laser ablation - Inductively coupled plasma - Mass spectrometry (LAICP-MS). Per. Mineral. 2008, 77, 3-21.

(20) Petrelli, M.; Morgavi, D.; Vetere, F.; Perugini, D. Elemental imaging and petro-volcanological applications of an improved Laser Ablation Inductively Coupled Quadrupole Plasma Mass Spectrometry. Per. Mineral. 2016, 85, 25-39.

(21) Pearce, N. J. G. G.; Perkins, W. T.; Westgate, J. A.; Gorton, M. P.; Jackson, S. E.; Neal, C. R.; Chenery, S. P. A Compilation of New and Published Major and Trace Element Data for NIST SRM 610 and NIST SRM 612 Glass Reference Materials. Geostand. Geoanal. Res. 1997, 21, 115-144.

(22) Liu, S.; Hu, Z.; Günther, D.; Ye, Y.; Liu, Y.; Gao, S.; Hu, S. Signal enhancement in laser ablation inductively coupled plasma-mass spectrometry using water and/or ethanol vapor in combination with a shielded torch. J. Anal. At. Spectrom. 2014, 29, 536-544.

(23) Shibata, N.; Fudagawa, N.; Kubota, M. Oxide formation in electrothermal vaporization inductively coupled plasma mass spectrometry. Spectrochim. Acta, Part B 1993, 48, 1127-1137.

(24) Guillong, M.; Danyushevsky, L.; Walle, M.; Raveggi, M. The effect of quadrupole ICPMS interface and ion lens design on argide formation. Implications for LA-ICPMS analysis of PGE's in geological samples. J. Anal. At. Spectrom. 2011, 26, 1401-1407.

(25) Nurubeili, T. K. Effect of Doubly Charged Ions in Forming the Mass Spectra of Solid-State Substances in a Mass Spectrometer with Inductively Coupled Plasma. Surf. Eng. Appl. Electrochem. 2018, 54, 395-400.

(26) Humayun, M.; Campbell, A. J. Microanalysis of niobium in iron meteorites. XXXIV Lunar Planet. Sci., 2003, Houston (CD-ROM). \#1480 (abstr.).

(27) Steenstra, E. S.; Berndt, J.; Klemme, S.; van Westrenen, W. LAICP-MS analyses of Fe-rich alloys: quantification of matrix effects for $193 \mathrm{~nm}$ excimer laser systems. J. Anal. At. Spectrom. 2019, 34, 222231.

(28) Paton, C.; Hellstrom, J. C.; Paul, B.; Woodhead, J. D.; Hergt, J. M. Iolite: Freeware for the visualization and processing of mass spectrometric data. J. Anal. At. Spectrom. 2011, 26, 2508-2518.

(29) Longerich, H. P.; Jackson, S. E.; Günther, D. Laser ablation inductively coupled plasma mass spectrometric transient signal data acquisition and analyte concentration calculation. J. Anal. At. Spectrom. 1996, 11, 899-904.

(30) Jochum, K. P.; Nohl, U.; Herwig, K.; Lammel, E.; Stoll, B.; Hofmann, A. W. GeoReM: A new geochemical database for reference materials and isotopic standards. Geostand. Geoanal. Res. 2005, 29, 333-338.

(31) Dauphas, N.; Pourmand, A. Thulium anomalies and rare earth element patternsin meteorites and Earth: Nebular fractionationand the nugget effect. Geochim. Cosmochim. Acta 2015, 163, 234-261. 
(32) Wood, B. J.; Smythe, D. J.; Harrison, T. The condensation temperatures of the elements: A reappraisal. Am. Mineral. 2019, 104, 844-856.

(33) Palme, H.; Lodders, K.; Jones, A. Solar System abundances of the elements. In Treatise on Geochemistry, 2nd ed.; Davis, A. M., Ed.; Elsevier-Pergamon: Oxford, 2014; pp 15-36.

(34) Lodders, K.; Fegley, B. The Planetary Scientist's Companion; Oxford Univ. Press: New York, 1998.

(35) Stracke, A.; Palme, H.; Gellissen, M.; Münker, C.; Kleine, T.; Birbaum, K.; Gunther, D.; Bourdon, B.; Zipfel, J. Refractory element fractionation in the Allende meteorite: Implications for solar nebula condensation and the chondritic composition of planetary bodies. Geochim. Cosmochim. Acta 2012, 85, 114-141.

(36) Braukmüller, N.; Wombacher, F.; Hezel, D. C.; Escoube, R.; Münker, C. The chemical composition of carbonaceous chondrites: Implications for volatile element depletion, complementarity and alteration. Geochim. Cosmochim. Acta 2018, 239, 17-48.

(37) Simon, S. B.; Davis, A. M.; Grossman, L. A unique ultrarefractory inclusion from the Murchison meteorite. Meteorit. Planet. Sci. 1996, 31, 106-115.

(38) Anders, E.; Grevesse, N. Abundances of the elements: Meteoritic and solar. Geochim. Cosmochim. Acta 1989, 53, 197-214.

(39) McDonough, W. F.; Sun, S. S. The composition of the earth. Chem. Geol. 1995, 120, 223-253.

(40) Kurat, G.; Koeberl, C.; Presper, T.; Brandstätter, F.; Maurette, M. Petrology and geochemistry of Antarctic micrometeorites. Geochim. Cosmochim. Acta 1994, 58, 3879-3904.

(41) Rudraswami, N. G.; Fernandes, D.; Naik, A. K.; Shyam Prasad, M.; Taylor, S. Fine-grained volatile components ubiquitous in solar nebula: Corroboration from scoriaceous cosmic spherules. Meteorit. Planet. Sci. 2018, 53, 1207-1222.

(42) Goderis, S.; Soens, B.; Huber, M. S.; McKibbin, S.; Ginneken, M.; Van Maldeghem, F.; Debaille, V.; Greenwood, R. C.; Franchi, I. A.; Cnudde, V.; Van Malderen, S.; Vanhaecke, F.; Koeberl, C.; Topa, D.; Claeys, P. Cosmic spherules from Widerøefjellet, Sør Rondane Mountains (East Antarctica). Geochim. Cosmochim. Acta 2020, 270, $112-143$.

(43) Oppenheim, J.; Chi, M.; Hu, J.; Bindi, L.; Steinhardt, P. J.; Asimow, P. D. Shock synthesis of decagonal quasicrystals. Sci. Rep. 2017, 7, No. 15628.

(44) Oppenheim, J.; Chi, M.; Hu, J.; Bindi, L.; Steinhardt, P. J.; Asimow, P. D. Shock synthesis of five-component icosahedral quasicrystals. Sci. Rep. 2017, 7, No. 15629.

(45) Richter, F. M.; Janney, P. E.; Mendybaev, R. A.; Davis, A. M.; Wadhwa, M. Elemental and isotopic fractionation of Type B CAI-like liquids by evaporation. Geochim. Cosmochim. Acta 2007, 71, 55445564.

(46) Ebel, D. S.; Grossman, L. Condensation in dust-enriched systems. Geochim. Cosmochim. Acta 2000, 64, 339-366.

(47) Lodders, K. Solar System Abundances and Condensation Temperatures of the Elements. Astrophys. J. 2003, 591, 1220-1247.

(48) MacPherson, G. J.; Davis, A. M. Refractory inclusions in the prototypical CM chondrite, Mighei. Geochim. Cosmochim. Acta 1994, $58,5599-5625$.

(49) Huang, S. C.; Farkas, J.; Yu, G.; Petaev, M. I.; Jacobsen, S. B. Calcium isotopic ratios and rare earth element abundances in refractory inclusions from the Allende CV3 chondrite. Geochim. Cosmochim. Acta 2012, 77, 252-265.

(50) Davis, A. M.; Zhang, J.; Greber, N. D.; Hu, J.; Tissot, F. L. H.; Dauphas, N. Titanium isotopes and rare earth patterns in CAIs: Evidence for thermal processing and gas-dust decoupling in the protoplanetary disk. Geochim. Cosmochim. Acta 2018, 221, 275-295.

(51) Cardelli, J. A. The abundance of heavy elements in interstellar gas. Science 1994, 265, 209-213.

(52) Savage, B. D.; Sembach, K. R. Interstellar abudances from absorption-line observations with the Hubble space telescope. Annu. Rev. Astron. Astrophys. 1996, 34, 279-329.
(53) Welty, D. E.; Hobbs, L. M.; Lauroesch, J. T.; Morton, D. C.; Spitzer, L.; York, D. G. Diffuse interstellar clouds toward 23 Orionis. Astrophys. J. Suppl. Ser. 1999, 124, 465-501.

(54) Yin, Q.-Z. "From Dust to Planets: The Tale Told by Moderately Volatile Elements", Chondrites and the Protoplanetary Disk, ASP Conference Series, Krot, A. N. et al.2005; pp 632-644.

(55) Wang, H.; Lineweaver, C. H. Chemical Complementarity between the Gas Phase of the Interstellar Medium and the Rocky Material of Our Planetary System, In Proceedings of the 15th Australian Space Research Conference, Short, W.; Caprarelli, G., Eds.; 2016; pp 173-182.

(56) Higuchi, H.; Ganapathy, R.; Morgan, J. W.; Anders, E. "Mysterite": a late condensate from the solar nebula. Geochim. Cosmochim. Acta 1977, 41, 843-851.

(57) Grossman, L.; Allen, J. M.; MacPherson, G. J. Electron microprobe study of a 'mysterite'-bearing inclusion from the Krymka LL-chondrite. Geochim. Cosmochim. Acta 1980, 44, 211-216.

(58) Ganapathy, R.; Larimer, J. W. A meteoritic component rich in volatile elements: its characterization and implications. Science 1980, 207, 57-59.

(59) Shu, F. H.; Shang, H.; Lee, T. Toward an astrophysical theory of chondrites. Science 1996, 271, 1545-1552.

(60) Fedkin, A. V.; Grossman, L.; Humayun, M.; Simon, S. B.; Campbell, A. J. Condensates from vapor made by impacts between metal-, silicate-rich bodies: comparison with metal and chondrules in CB chondrites. Geochim. Cosmochim. Acta 2015, 164, 236-261.

(61) Norris, C. A.; Wood, B. J. Earth's volatile contents established by melting and vaporization. Nature 2017, 549, 507-510.

(62) Sossi, P. A.; Fegley, B. Thermodynamics of element volatility and its application to planetary processes. Rev. Mineral. Geochem. 2018, 84, 393-459.

(63) Fegley, B.; Schaefer, L. Treatise on Geochemistry, 2nd ed.; Holland, H. D.; Turekian, K. K., Eds.; Elsevier: Oxford, 2014; Vol. 71.

(64) Lock, S. J.; Stewart, S. T. The structure of terrestrial bodies: Impact heating, co-rotation limits, and synestias. J. Geophys. Res.: Planets 2017, 122, 950-982.

(65) Mahan, B.; Siebert, J.; Blanchard, I.; Badro, J.; Kubik, E.; Sossi, P.; Moynier, F. Investigating Earth's formation history through copper and sulfur metal-silicate partitioning during core-mantle differentiation. J. Geophys. Res.: Solid Earth 2018, 123, 8349-8363.

(66) Davies, E. J.; Carter, P. J.; Root, S.; Kraus, R. G.; Spaulding, D. K.; Stewart, S. T.; Jacobsen, S. B. Silicate melting and vaporization during rocky planet formation. J. Geophys. Res.: Planets 2020, 125, No. e2019JE006227.

(67) Essene, E. J.; Fisher, D. C. Lightning strike fusion: Extreme reduction and metal-silicate liquid immiscibility. Science 1986, 234, 189-193.

(68) Desch, S. J.; Cuzzi, J. N. The generation of lighting in the solar nebula. Icarus 2000, 143, 87-105.

\section{NOTE ADDED AFTER ASAP PUBLICATION}

This paper was originally pubished ASAP on February 25, 2021. Corrections were made to the formulas in the first sentence of the Abstract, and the paper was reposted on March 2, 2021. 